\title{
Optimized Peptide-MHC Multimer Protocols for Detection and Isolation of Autoimmune T-Cells
}

\section{OPEN ACCESS}

Edited by:

Nick Gascoigne,

National University of

Singapore, Singapore

Reviewed by:

Salvatore Valitutti, Institut National de la Santé et de la Recherche Médicale

(INSERM), France

Sidonia Barbara Guiomar Eckle,

University of Melbourne, Australia

Preeti Sharma,

University of Illinois at Urbana-

Champaign, United States

*Correspondence:

Andrew K. Sewell sewellak@cardiff.ac.uk

Specialty section: This article was submitted to T Cell Biology,

a section of the journal

Frontiers in Immunology

Received: 12 March 2018 Accepted: 04 June 2018

Published: 29 June 2018

Citation:

Dolton G, Zervoudi E, Rius C, Wall A,

Thomas HL, Fuller A, Yeo L, Legut M,

Wheeler S, Attaf M, Chudakov DM,

Choy E, Peakman M and Sewell AK

(2018) Optimized Peptide-MHC

Multimer Protocols for Detection and Isolation of Autoimmune T-Cells.

Front. Immunol. 9:1378. doi: 10.3389/fimmu.2018.01378

\begin{abstract}
Garry Dolton ', Efthalia Zervoudi ', Cristina Rius', Aaron Wall', Hannah L. Thomas ', Anna Fuller ${ }^{1}$, Lorraine Yeo ${ }^{2,3}$, Mateusz Legut ${ }^{1}$, Sophie Wheeler ${ }^{1}$, Meriem Attaf ${ }^{1}$, Dmitriy M. Chudakov ${ }^{4,5,6}$, Ernest Choy ${ }^{1,7}$, Mark Peakman ${ }^{2,3}$ and Andrew K. Sewell ${ }^{1,7 *}$

${ }^{1}$ Division of Infection and Immunity, Cardiff University School of Medicine, Cardiff, United Kingdom, ${ }^{2}$ Department of Immunobiology, Faculty of Life Sciences and Medicine, King's College London, London, United Kingdom, ${ }^{3}$ NIHR Biomedical Research Centre at Guy's and St Thomas' NHS Foundation Trust and King's College London, London, United Kingdom, ${ }^{4}$ Pirogov Russian National Research Medical University, Moscow, Russia, ${ }^{5}$ Centre for Data-Intensive Biomedicine and Biotechnology, Skolkovo Institute of Science and Technology, Skolkovo, Russia, ${ }^{6}$ Shemyakin and Ovchinnikov Institute of Bioorganic Chemistry, Moscow, Russia, ${ }^{7}$ Systems Immunity Research Institute, Cardiff University, Cardiff, United Kingdom
\end{abstract}

Peptide-MHC (pMHC) multimers have become the "gold standard" for the detection and isolation of antigen-specific T-cells but recent evidence shows that normal use of these reagents can miss fully functional T-cells that bear T-cell receptors (TCRs) with low affinity for cognate antigen. This issue is particularly pronounced for anticancer and autoimmune T-cells as self-reactive T-cell populations are enriched for low-affinity TCRs due to the removal of cells with higher affinity receptors by immune tolerance mechanisms. Here, we stained a wide variety of self-reactive human T-cells using regular pMHC staining and an optimized technique that included: (i) protein kinase inhibitor (PKI), to prevent TCR triggering and internalization, and (ii) anti-fluorochrome antibody, to reduce reagent dissociation during washing steps. Lymphocytes derived from the peripheral blood of type 1 diabetes patients were stained with pMHC multimers made with epitopes from preproinsulin (PPI), insulin- $\beta$ chain, glutamic acid decarboxylase 65 (GAD65), or glucose-6-phospate catalytic subunit-related protein (IGRP) presented by disease-risk allelles HLA $A^{\star} 02: 01$ or HLA*24:02. Samples from ankylosing spondylitis patients were stained with a multimerized epitope from vasoactive intestinal polypeptide receptor 1 (VIPR1) presented by HLA B 27:05. Optimized procedures stained an average of 40.5 -fold ( $p=0.01$, range between 1.4 and 198) more cells than could be detected without the inclusion of PKI and cross-linking anti-fluorochrome antibody. Higher order pMHC dextramers recovered more cells than pMHC tetramers in parallel assays, and standard staining protocols with $\mathrm{pMHC}$ tetramers routinely recovered less cells than functional assays. HLA $A^{\star} 02: 01$-restricted PPI-specific and HLA B*27:05restricted VIPR1-specific T-cell clones generated using the optimized procedure could not be stained by standard pMHC tetramer staining. However, these clones responded well to exogenously supplied peptide and endogenously processed and presented epitopes. We also showed that anti-fluorochrome antibody-conjugated magnetic beads enhanced staining of self-reactive T-cells that could not be stained using standard protocols, thus enabling rapid ex vivo isolation of autoimmune T-cells. We, therefore, 
conclude that regular pMHC tetramer staining is generally unsuitable for recovering self-reactive T-cells from clinical samples and recommend the use of the optimized protocols described herein.

Keywords: peptide-MHC multimer, tetramer, dextramer, autoimmune disease, T-cell, type 1 diabetes, ankylosing spondylitis, cancer epitope

\section{INTRODUCTION}

Conventional T-cells orchestrate the immune response to pathogens by recognizing foreign protein antigens in the form of peptides presented at the cell surface bound to MHC molecules. The key to recognition lies in the heterodimeric $\alpha \beta$ $\mathrm{T}$-cell receptor (TCR) which, in concert with either the CD4 or $\mathrm{CD} 8$ coreceptor, engages peptide-MHC (pMHC) to produce an intracellular transduction cascade that results in T-cell activation (1-3). TCR-pMHC binding parameters are selected in the thymus via recruitment of the signal-initiating kinase Lck, which is sequestered by the intracellular tails of CD4 and CD8 (4). These coreceptors bind to sites on MHC class I and class II, respectively, that are distinct from the TCR-docking platform thereby enabling formation of TCR-pMHCI-CD8 or TCRpMHCII-CD4 quadripartite complexes $(3,4)$. The privileged delivery of Lck to the cytoplasmic side of the TCR/CD3 complex by the T-cell coreceptors ensures that TCRs are MHC-restricted (5-7) and selects the TCR-pMHC dwell time that permits onward thymic development and release into the periphery (4). T-cells bearing TCRs that do not interact with self pMHC die by neglect in the absence of a positive selection signal (8). At the other extreme, cells bearing TCRs that bind strongly to self pMHC, and thereby have potential to react to self, are eliminated from the pool of developing T-cells (8). This central tolerance mechanism ensures that T-cells with TCRs that interact strongly with self-peptides do not enter the peripheral tissues and, in conjunction with peripheral tolerance mechanisms, explains why self-reactive TCRs bind with lower affinity, and with shorter dwell times than TCRs specific for foreign, pathogen-derived peptides $(9,10)$. Indeed, the best anti-pathogen TCRs tend to bind with TCR affinities with dissociation constants $\left(K_{\mathrm{D}} \mathrm{s}\right)$ in the range of $0.1-10 \mu \mathrm{M}$ by surface plasmon resonance (SPR) whereas self-reactive TCRs isolated from anticancer and autoimmune T-cells bind with much weaker affinities $\left(K_{\mathrm{D}}\right.$ 20-500 $\mu \mathrm{M})(9-11)$. Functional assays using modified TCRs with enhanced affinities indicate that the most sensitive T-cells tend to have TCRs that bind with $K_{D}$ s between 0.1 and $3 \mu \mathrm{M}$, which sit at the higher end of the natural anti-pathogen TCR affinity range (9-11). Further engineered increases in TCR affinity are generally detrimental as they are thought to impede the serial triggering of many TCRs by a single agonist pMHC and can result in recognition of self-peptides $(12,13)$. Thus, T-cell development imposes a dwell time "window" on the TCRs of peripheral T-cells that is of sufficient duration to allow TCR triggering but short enough to enable serial triggering of multiple receptors by each agonist pMHC (14). In general, anti-pathogen TCRs sit at the stronger end of this affinity window, followed by anticancer TCRs $(1,9,10)$, whereas autoimmune TCRs reside at the other end of the spectrum and can have TCRs that bind very weakly $\left(K_{\mathrm{D}}>150 \mu \mathrm{M}\right)[(10,15)$ and unpublished data] (Figure 1).

Although TCR engagement with cognate pMHC is shortlived, this interaction can be stabilized by the "avidity effect" afforded by incorporating multiple pMHC on a single molecule (17). This effect was originally taken advantage of by combining soluble biotinylated pMHC with fluorochrome-conjugated streptavidin. The resultant pMHC tetramers can bind stably to cognate T-cells within peripheral blood mononuclear cells (PBMC) to allow detection and phenotyping of antigen-specific T-cells directly ex vivo. Since their initial adoption in 1996 (18), pMHC tetramers have been used in many thousands of studies and it is no exaggeration to say that they have revolutionized the study of antigen-specific T-cell populations in ex vivo samples (19). Various pMHC multimerization platforms have been utilized, most of which are commercially available [reviewed in Ref. $(17,20)]$. In 2007, we described how the affinity required for stabilization of pMHC tetramer binding was considerably higher than that required for T-cell activation (21). Consequently, standard pMHC tetramer staining fails to reveal fully functional T-cells that bear TCRs below the limits of detection. This deficiency precipitated the development of various methodologies aimed at lowering the TCR affinity threshold for pMHC multimer staining (summarized in Table 1).

We currently utilize an optimized pMHC multimer staining procedure that incorporates two simple, inexpensive, broadly applicable improvements that can be used with pMHCI and pMHCII reagents and aids staining in all species tested to date, including human, mouse, monkey, and pig (32-35). The first of these improvements involves inclusion of 50nM Dasatinib, a protein kinase inhibitor (PKI), to prevent TCR downregulation (32). In addition, we include an anti-fluorochrome antibody $(\mathrm{Ab})$ to cross-link pMHC multimers at the T-cell surface. Such cross-linking can result in substantial improvements in pMHC multimer staining by stabilizing binding and limiting dissociation during washing steps (33). Here, we apply standard pMHC tetramer staining and an optimized protocol including PKI and cross-linking $\mathrm{Ab}(\mathrm{PKI}+\mathrm{Ab})$ when staining clinical samples with a wide range of self-epitopes relevant to type 1 diabetes (T1D) and ankylosing spondylitis. The optimized protocol was found to be up to two orders of magnitude more effective, in terms of cell numbers recovered and brightness of staining, than parallel staining in the absence of PKI + Ab. Importantly, T-cell clones isolated by optimized pMHC multimer staining could not be stained with cognate antigen in the absence of PKI $+\mathrm{Ab}$ despite being fully functional, i.e., able to recognize targets in the presence of exogenously supplied peptide or endogenously processed and presented antigen. 


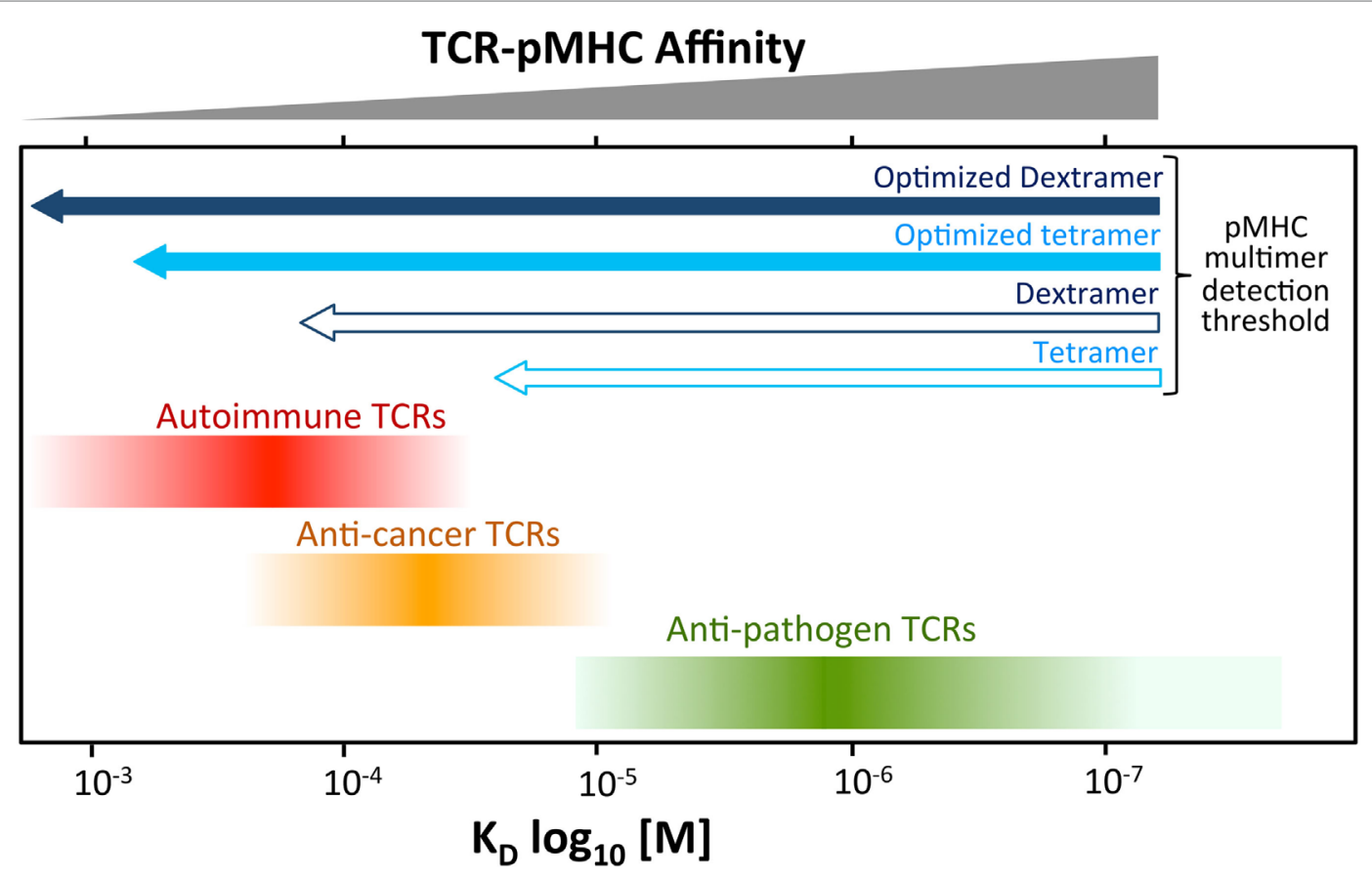

FIGURE 1 | Self-reactive T-cells have low-affinity T-cell receptors (TCRs). Anti-pathogen TCRs tend to bind to cognate Peptide-MHC (pMHC) with relatively high affinity $\left(K_{D}<20 \mu \mathrm{M}\right)$. The rigors of central tolerance ensure that autoimmune TCRs bind with much weaker affinity. Anticancer TCRs tend to sit between these two extremes. This schematic depicts a general overview of what is normally observed. A minority of TCRs do not obey these general rules. Cancer TCRs that bind to unstable pMHC have been described can have higher affinites $\left(K_{D} \sim 15 \mu \mathrm{M}\right)(16)$. TCRs specific for cancer neoantigens (non-self) may behave more like pathogenspecific TCR. The arrows at the top indicate the rough affinity detection threshold of TCRs amenable to staining with standard pMHC multimer staining and an optimized procedure including protein kinase inhibitor and antibody cross-linking. Optimized staining with pMHC tetramers is believed to detect almost all antigen-specific T-cells. An optimized dextramer is only required when staining the very weakest of functional autoimmune T-cells.

TABLE 1 | Methods for improving peptide-MHC (pMHC) multimer staining

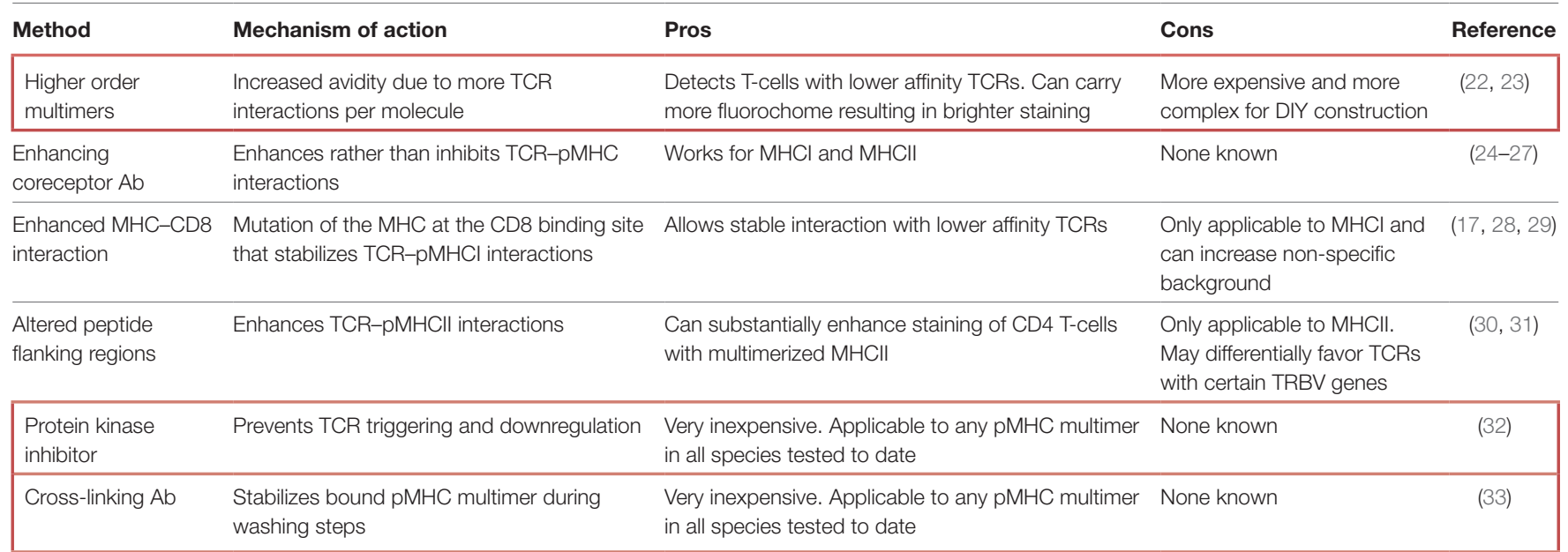

Only the methods boxed in red were utilized in this study.

\section{MATERIALS AND METHODS}

\section{Patient Material and Ethical Approval Statement}

Cryopreserved PBMCs from patients with T1D were obtained with the approval of a national research ethics committee, and informed consent was obtained from all participants. Ankylosing spondylitis patients were recruited locally from the clinic (Cardiff Regional Experimental Arthritis Treatment and Evaluation Centre) and anonymized whole blood used for preparation of PBMCs. Patients gave informed consent in accordance with the Research Ethics Committee for Wales (12/WA/0045). PBMC 
were obtained from a further HLA $B^{\star 27: 05}$ ankylosing spondylitis patient diagnosed at the Institute of Rheumatology, Russian Academy of Medical Sciences, Moscow, Russia, in accordance with modified New York criteria (36). This patient gave written informed consent prior to enrolling in the study. The study was approved by the local ethical committee of Pirogov Russian National Research Medical University, Moscow, Russia. This patient has been the subject of several previous studies (37-39).

\section{Peptide Epitopes}

The peptide epitopes and their restricting HLA and disease relevance are listed in Table 2.

\section{T-Cell Culture and Cloning}

T-cell clones and lines were cultured in T-cell media (RPMI-1640, $10 \%$ fetal bovine serum (FBS), $2 \mathrm{mM}$ L-glutamine, $100 \mathrm{U} / \mathrm{mL}$ penicillin, $100 \mu \mathrm{g} / \mathrm{mL}$ streptomycin, $10 \mathrm{mM}$ HEPES buffer, $0.5 \times$ non-essential amino acids, and $1 \mathrm{mM}$ sodium pyruvate, all from Life Technologies, Carlsband, CA, USA) supplemented with 200 IU of IL-2 (Aldesleukin, Proleukin, Prometheus, San Diego, CA, USA) and $25 \mathrm{ng} / \mathrm{mL}$ human IL-15 (Peprotech, Rocky Hill, NJ, USA). T-cells were stimulated for expansion every $2-5$ weeks with irradiated (3,000-3,100 cGy) allogeneic PBMCs from three donors and $1-2 \mu \mathrm{g} / \mathrm{mL}$ of phytohemagglutinin (Alere, Thermo Scientific, Walthan, MA, USA). T-cell clones were procured by limiting dilution as previously described (51) and expanded as described above. T-cells were cultured for a minimum of 2 weeks post-restimulation before being used for experiments.

\section{Generation of Immortalized B-Cells}

Lymphoblastoid cell lines (LCLs) were created from PBMCs by incubation with Epstein-Barr virus (EBV) containing supernatant from the B95-8 cell line. Media (36-48 h of culture) from Cotton-top Tamarin monkey B95-8 cell line (European Collection of Authenticated Cell Cultures, catalogue number 85011419) at $80-90 \%$ confluence was harvested, centrifuged at $400 \mathrm{~g}$ for $5 \mathrm{~min}$, $0.22-\mu \mathrm{m}$ filtered, and stored at $-80^{\circ} \mathrm{C}$. PBMCs $\left(1-5 \times 10^{6}\right)$ were cultured in $1 \mathrm{~mL}$ R10 medium (RPMI, 10\% FCS, L-glutamine, penicillin, and streptomycin) with $1 \mathrm{~mL}$ of B95-8 supernatant with $4 \mu \mathrm{g} / \mathrm{mL}$ of cyclosporin A (Sigma-Aldrich, St. Louis, MO, USA). Cells were passaged as required, and cyclosporin A treatment continued for 2 weeks.

\section{Expressing Transgenic Self-Proteins}

A K562 cell line expressing HLA A*02:01 and preproinsulin was generated and cultured as previously described (42). Patient LCLs were made to express vasoactive intestinal polypeptide receptor 1 (VIPR 1 ) or the $\alpha 2$ chain of collagen type VI. Codon optimized full-length VIPR1 (UniProtKB P32241) or COL6A2 (UniProtKB P12110) cDNAs were synthesized (Genewiz, South Plainfield, NJ, USA) and cloned into the third generation lentiviral transfer vector pELNS (kindly provided by Dr. James Riley, University of Pennsylvania, PA, USA). The pELNS vector contains a rat $\mathrm{CD} 2$ ( $\mathrm{rCD} 2)$ marker gene separated from the gene of interest by a self-cleaving $2 \mathrm{~A}$ sequence. Lentiviral particle production by calcium chloride transfection and rCD2-based purification of lentivirally transduced cells were performed as previously described (52).

\section{pMHC Multimers and Flow Cytometry}

Monomeric pMHCs were generated in-house (53) and used to assemble tetramer and dextramers as previously described $(22,33)$. Premium grade R-Phycoerythrin conjugated streptavidin (SA) was purchased from Life Technologies (catalog number S21388). R-Phycoerythrin conjugated SA dextramer backbone was sourced from Immudex Limited (Copenhagen, Denmark). Tetramers and dextramer were stored at $4^{\circ} \mathrm{C}$ in the dark with added protease inhibitors (1:100 of set 1 , Merck, London, UK) and used within three days of being assembled. Clones/lines/PBMCs were harvested from culture or recently defrosted cells, washed ( $400 \mathrm{~g}, 5 \mathrm{~min})$, counted, and placed in $5 \mathrm{~mL}$ polypropylene tubes suitable for flow cytometry. Typically, $2 \times 10^{4}$ of a clone, $1 \times 10^{5}$ of a line, or $3 \times 10^{6}$ PBMCs were used for staining. The cells were washed with FACS buffer $(\mathrm{PBS}+2 \% \mathrm{FBS})$.

TABLE 2 | T-cell epitopes used in this study.

\begin{tabular}{|c|c|c|c|c|}
\hline HLA-restriction & Peptide sequence & Protein origin (and residues) & Disease relevance & Reference \\
\hline$A^{*} 02: 01$ & NLVPMVATV & Cytomeglavirus (CMV) pp65 (495-503) & CMV infection (control) & $(40)$ \\
\hline$A^{*} 02: 01$ & ILAKFLHWL & $\begin{array}{l}\text { Human telomerase reverse transcriptase } \\
\text { (hTERT) (540-548) }\end{array}$ & Not natural (control) & $(41)$ \\
\hline$A^{*} 02: 01$ & ALWGPDPAAA & Preproinsulin (PPI) (15-24) & Type 1 diabetes (T1D) & $(42)$ \\
\hline$A^{*} 02: 01$ & VMNILLQYVV & Glutamate decarboxylase 65 (GAD65) (114-123) & $\mathrm{T} 1 \mathrm{D}$ & (43) \\
\hline$A^{*} 02: 01$ & VLFGLGFAI & $\begin{array}{l}\text { Islet-specific glucose-6-phosphatase catalytic } \\
\text { subunit-related protein (IGRP) (265-273) }\end{array}$ & T1D & $(44)$ \\
\hline$A^{\star} 02: 01$ & MVWESGCTV & Islet Antigen-2 (IA-2) (795-805) & T1D & $(45)$ \\
\hline$A^{*} 02: 01$ & HLVEALYLV & Insulin- $\beta$ chain (10-18) & T1D & $(46)$ \\
\hline$A^{*} 02: 01$ & NLSALGIFST & $\begin{array}{l}\text { Insulin-like growth factor } 2 \text { mRNA binding protein } 2 \\
\text { (IMP2) (367-376) }\end{array}$ & Cancer & Unpublished \\
\hline$A^{\star} 24: 02$ & LWMRLLPLL & PPI (3-11) & T1D & $(47)$ \\
\hline$B^{\star} 27: 05$ & KRWILLGLNK & HIV p24 gag (263-27) & HIV infection (control) & $(48)$ \\
\hline$B^{\star} 27: 05$ & RRKWRRWHL & $\begin{array}{l}\text { Vasoactive intestinal polypeptide receptor } 1 \\
\text { (VIPR1) (400-408) }\end{array}$ & Ankylosing spondylitis & $(49)$ \\
\hline$B^{\star 2} 27: 05$ & DRASFIKNL & Collagen type VI $\alpha 2$ subunit (114-122) & Ankylosing spondylitis & $(50)$ \\
\hline
\end{tabular}

Shaded based on HLA restriction. 


\section{Optimized pMHC Multimer Staining}

An overview of the optimized staining protocols used in this study can be found in Figure S1 in Supplementary Material. Cells were pretreated with the PKI (50 nM) Dasatinib (Axon Medchem, VA, USA), for 5-60 min (typically $30 \mathrm{~min}$ ) at $37^{\circ} \mathrm{C}$ in $100 \mu \mathrm{L}: 50 \mu \mathrm{L}$ of residual fluid and $50 \mu \mathrm{L}$ of $2 \times$ PKI $(100 \mathrm{nM})$ in PBS. PKI was stored as $1 \mathrm{mM}$ single use DMSO stocks at $-80^{\circ} \mathrm{C}$. The flexibility of the incubation time needed for PKI allows either a "fast-track" staining protocol (5 min with $\mathrm{PKI}$ ) to be performed or allows time to prepare other reagents needed for the assay $(<60 \mathrm{~min}$ with PKI). PE-conjugated tetramers or dextramers were spun in a microfuge to remove aggregates (full speed for $1 \mathrm{~min}$ ), and then $0.5 \mu \mathrm{g}$ (with respect to pMHC component) added directly to each sample without washing or pre-chilling, followed by incubation for $30 \mathrm{~min}$ on ice and in the dark. Cells were washed with $3 \mathrm{~mL}$ of FACS buffer $(700 \mathrm{~g}, 3 \mathrm{~min})$ and $0.5 \mu \mathrm{g}(10 \mu \mathrm{g} / \mathrm{mL})$ of mouse anti-PE unconjugated Ab (clone PE001, BioLegend, London, UK) added to each sample for $20 \mathrm{~min}$ on ice and in the dark. Whereas we used PE-conjugated pMHC multimers for this study, other fluorochrome, for instance allophycocyanin (APC), conjugated tetramers or dextramers can also be used with the optimized protocol, by matching the anti-fluorochrome $\mathrm{Ab}$ to the pMHC multimer, as previously described (53). Cells were washed with $3 \mathrm{~mL}$ of PBS (700 $\mathrm{g}, 3 \mathrm{~min})$ to remove residual serum and incubated for 5 min at RT with $2 \mu \mathrm{L}$ of LIVE/DEAD fixable dead cell stain (Vivid; Life Technologies) that had been diluted 1:40 using PBS. Ab cocktails to detect surface markers were added directly to each sample without washing. For clones, anti-CD8APC or -APC Vio770 ${ }^{\mathrm{TM}}$ (clone BW135/80, Miltenyi Biotech) and anti-CD3-peridinin chlorophyll (clone BW264/56, Miltenyi Biotech) were used. For lines and PBMCs, anti-CD19-pacific blue (PB) (clone HIB19, BioLegend) and anti-CD14-PB (clone M5E2, BioLegend) Abs were also included. Cells were washed with $3 \mathrm{~mL}$ of FACS buffer and resuspended in $50 \mu \mathrm{L}$ of FACS buffer. Although not performed in this study, samples can be fixed with $2 \%$ paraformaldehyde (PFA) by washing with $3 \mathrm{~mL}$ of PBS, incubating with $50 \mu \mathrm{L}$ of $4 \%$ PFA (added to the $50 \mu \mathrm{L}$ of residual PBS left after washing) on ice for $20 \mathrm{~min}$ in the dark, washing again with $3 \mathrm{~mL}$ of PBS, decanting, then storing at $4^{\circ} \mathrm{C}$ in the dark ready for flow cytometry the following day. Samples were vortexed throughout the staining protocol, both prior and post the addition of reagents.

\section{Standard pMHC Staining}

The standard protocol was performed in the same manner as the optimized, but without addition of PKI or anti-PE Ab. For the comparative purpose of this study, cells were mock treated with PKI by the addition of $50 \mu \mathrm{L}$ of PBS.

\section{Flow Cytometry and Analysis}

For acquisition cells were run a BD FACS Canto II (BD Biosciences) and for sorting on a BD FACS Aria (BD Biosciences) run by Central Biotechnology Services (Cardiff University, Wales, UK). Sequential gating strategy for tetramer and dextramer analyses; Gate 1: lymphocytes; Gate 2: single cells; Gate 3: $\mathrm{CD}^{+}{ }^{+}$Vivid $^{\text {neg }} \mathrm{CD} 19^{\text {neg }} \mathrm{CD} 14^{\text {neg }}$ cells; then displayed as dot plots (CD8 versus tetramer or dextramer) or histograms of tetramer or dextramer fluorescence. Smoothed zebra plots with outliers shown as large dots were used for the display of dot plots. FlowJo software (TreeStar, Inc., Ashland, OR, USA) was used to analyze the data.

\section{Magnetic Bead Enrichment}

Peripheral blood mononuclear cells were treated and incubated with PKI and dextramers as above (Figure S1 in Supplementary Material for protocol schematic). Cells were washed in ice cold MACS buffer (D-PBS without calcium and magnesium ions, $0.5 \%$ bovine serum albumin (both Sigma-Aldrich), and 2 mM EDTA, $\mathrm{pH}$ 7.2-7.5). Anti-PE magnetic microbeads were used according to the manufacturer's instructions, whereby $80 \mu \mathrm{L}$ of MACS buffer and $20 \mu \mathrm{L}$ of beads were used per $1 \times 10^{7}$ cells, with no scaling down for lower cell numbers. Positive cells were collected by centrifugation ( $400 \mathrm{~g}$ for $5 \mathrm{~min}$ ) and incubated overnight in a single well of a 96-U-well plate, in T-cell media. Cells were expanded in the same well with PHA and allogenic PBMCs, as described above.

\section{Functional Assays}

\section{TNF Processing Inhibitor-0 (TAPI-0) Assay}

Cells were harvested from culture washed with R0 (as for R10 but with no FBS) and rested overnight in R5 media (as for R10 but with 5\% FBS). Resting ensured minimal background activation of the T-cells. On the day of activation assay, cells were harvested, and $2-5 \times 10^{4}$ cells were incubated with $30 \mu \mathrm{M}$ TAPI-0 (SigmaAldrich) (54) anti-TNF-PE-Vio770 ${ }^{\mathrm{TM}}$ (clone cA2, Miltenyi Biotech) and anti-CD107a-PE (clone H4A3, BD Biosciences) Abs in well(s) of a $96 \mathrm{U}$-well plate. For peptide presentation, autologous LCLs were used for clonal T-cells, and T-cell to T-cell presentation used for T-cell lines. The cells were incubated for $4-5 \mathrm{~h}$ at $37^{\circ} \mathrm{C}$ then stained with Vivid and Abs for CD3 and/or $\mathrm{CD} 8$, as above.

\section{Enzyme-Linked Immunosorbent Assay (ELISA)}

Prior to assay, T-cell clones were rested overnight in R5. Clonal CD8 T-cells $\left(3 \times 10^{4}\right.$ per well $)$ were incubated overnight at $37^{\circ} \mathrm{C}$. Autologous LCLs or T2 cells (ATCC CRL-1992) were used as antigen presenting cells for clonal T-cells. Supernatants were harvested the following morning and assayed for macrophage inflammatory protein (MIP)-1 $\beta$ by ELISA according to the manufacturer's instructions (R\&D Systems, Minneapolis, MN, USA).

\section{RESULTS}

\section{Superior Detection of Pancreatic Peptide- Specific T-Cells With an Optimal Tetramer Staining Protocol}

Four HLA class I alleles have been linked to T1D, namely HLAs $A^{\star} 02: 01, A^{\star} 24: 02, B^{\star} 18: 01$, and $B^{\star} 39: 06$ (55). Due to the prevalence of some of these alleles in the general population, the vast majority of T1D patients carry either HLA $A^{*} 02: 01$ or HLA A $^{\star} 24: 02$ so these alleles were chosen for this study. Several pancreatic $\beta$-cell-specific epitopes that are presented by these alleles have been defined $(42,44,47,56,57)$. Purified CD8 T-cells 
from an HLA $\mathrm{A}^{\star} 02: 01^{+}$type I diabetes patient were stimulated with peptides from CMV, GAD65, IGRP, IA-2, and the insulin- $\beta$ chain (Table 2) to create T-cell lines for testing with standard and optimized tetramer staining protocols (Figure 2A) (see Figure S1 in Supplementary Material for optimized protocol schematic). The control CMV line stained well with the pp65 tetramer under standard conditions with clear separation between the tetramer ${ }^{\text {neg }}$ and tetramer ${ }^{+}$cells (Figure 2B), which is characteristic of standard staining for many antiviral T-cell populations (22). Prior to cognate multimer staining, $\mathrm{T}$-cell lines that had been stimulated with pancreatic $\beta$-cell-specific epitopes were assessed for reactivity against exogenously supplied peptides by measuring CD107a (58) and TNF (54) expression. No specific response was observed in lines stimulated with IGRP and IA2 peptides, and the lines were discarded. In contrast, the lines stimulated with insulin- $\beta$ chain and GAD65 peptides expressed TNF/CD107a in response to cognate antigens (Figure $\mathbf{2 C}$ ). These peptide-reactive T-cell lines were subsequently stained with irrelevant and cognate pancreatic peptide-HLA $A^{\star}$ 02:01 PE-conjugated tetramers. The percentage of tetramer ${ }^{+}$cells increased when using the optimized protocol compared to the standard approach; in both cases, the optimized protocol resulted in approximately sixfold increase in the percentage of detected cells (Figure 2C). Importantly, the tetramer ${ }^{+}$populations became more discernible from the tetramer ${ }^{\text {neg }}$ cells when using the optimized protocol. Furthermore, the percentage of peptide-specific cells detected with the optimized protocol correlated better with the functional response to exogenously supplied peptides, while standard tetramer staining vastly underestimated the fraction of peptide-reactive cells. Overall, the inclusion of two inexpensive reagents, the PKI Dasatinib and anti-fluorochrome Ab, to create an optimal tetramer staining protocol allowed autoimmune T-cells to be detected with relative ease.

\section{Optimal Staining With pMHC Dextramers Further Improves the Detection of Autoimmune T-Cells}

We next examined the $\mathrm{PPI}_{15-24}$ T-cell line grown as above. Even using the optimized tetramer staining protocol, we managed to detect only 10 -fold less cells than detected in the parallel functional assay (Figure 3A). We then turned to using pMHC dextramers as we had previously demonstrated that these higher order reagents can extend the TCR affinity threshold that is amenable to pMHC multimer staining (Figure 1 and reagent schematic in Figure 3A) (22). Standard pMHC dextramer staining recovered a population of CD8 T-cells of similar size to that recovered with an optimized $\mathrm{pMHC}$ tetramer procedure
A

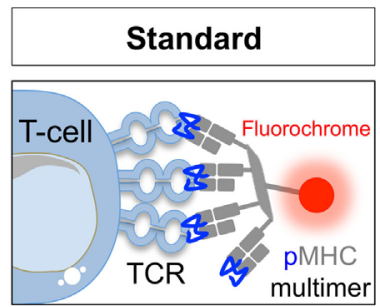

Optimized

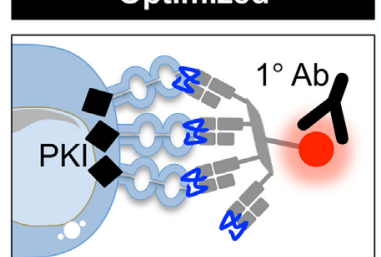

B

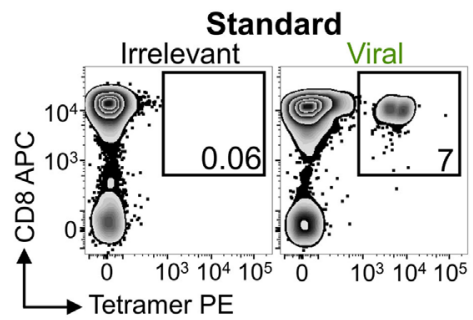

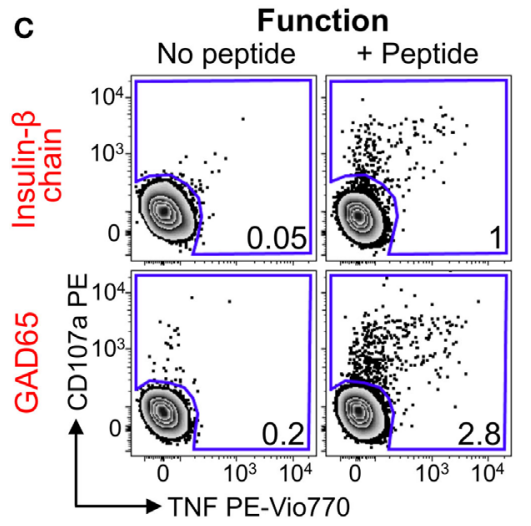
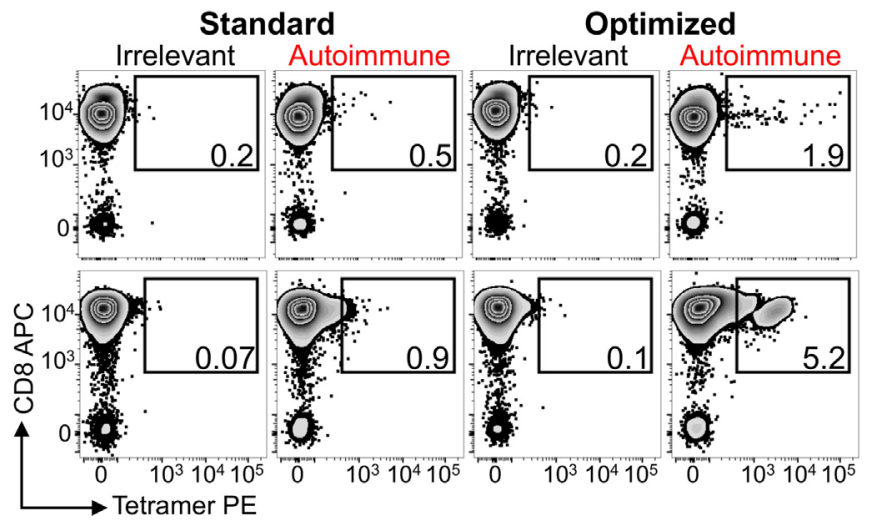

FIGURE 2 | Enhanced detection of autoimmune T-cells from a type I diabetic patient using optimal tetramer staining techniques. (A) Standard and optimal tetramer staining approaches to detect antigen-specific T-cells. Optimal staining uses the protein kinase inhibitor (PKI) Dasatinib to treat T-cells before staining with tetramer and then an unconjugated anti-fluorochrome Ab. We have previously described the use of conjugated secondary antibodies to bind the primary antibody, adding further fluorescence to peptide-MHC multimers labeled T-cells, but for the purpose of this study only the primary cross-linking antibody was used. T-cell receptor (TCR). (B) Sorted CD8 T-cells from a HLA A*02:01+ patient with type I diabetes were stimulated with a peptide from CMV (pp65 $495-503$, NLVPMVATV) and then stained 2 weeks later with irrelevant (hTERT $540-548$, ILAKFLHWL) or CMV tetramers using standard conditions. (C) From the same patient in (B) CD8 T-cells were

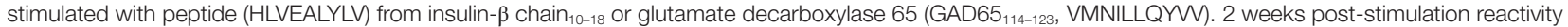
toward the respective peptide (100 nM) was assessed by co-incubation with TAPI-0 and detection of CD107a and TNF (left panel). The T-cell lines were stained with PE-conjugated irrelevant (as above) and respective autoimmune tetramers using standard or optimal conditions (right panel). The percentage of cells residing in each gate are shown. 

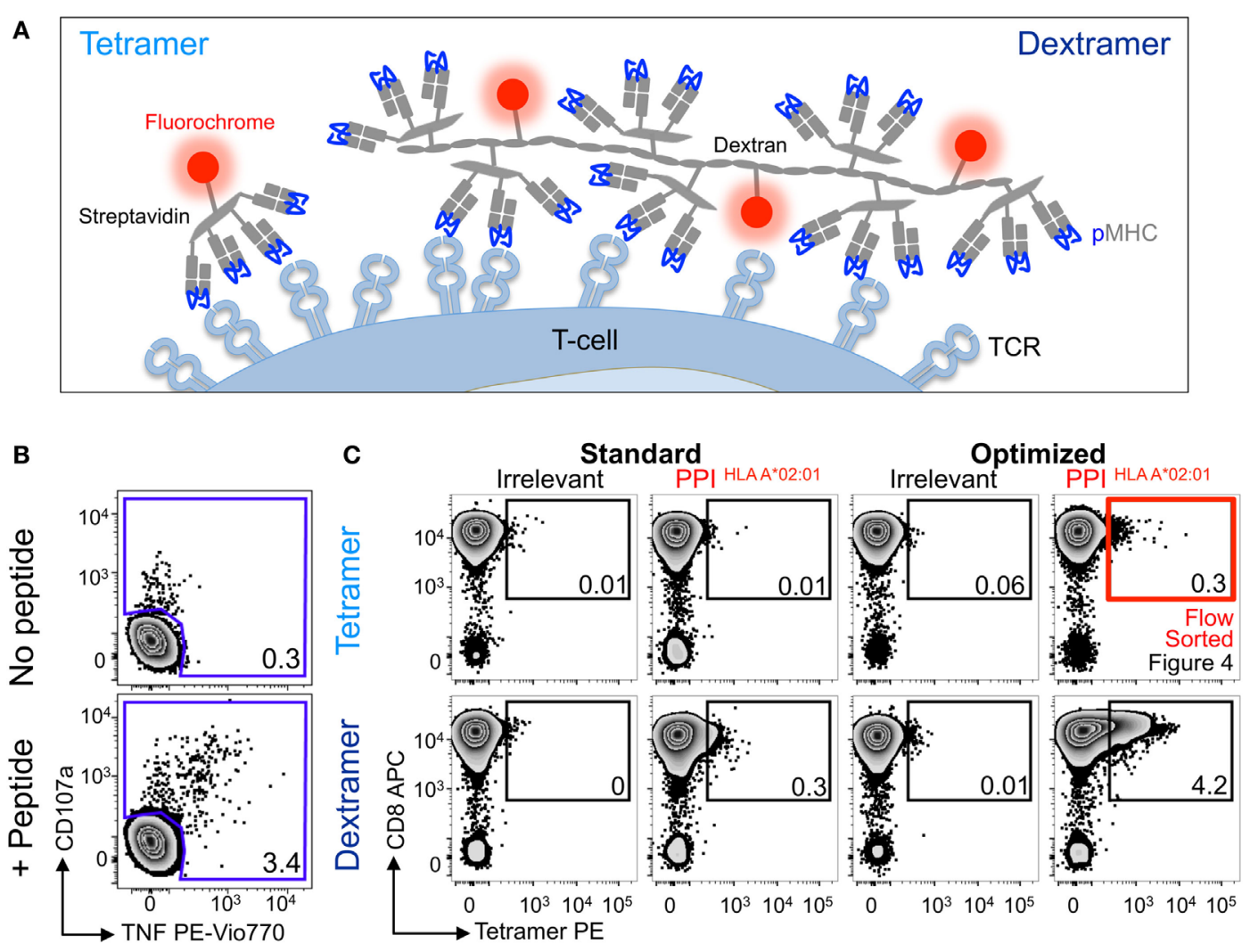

FIGURE 3 | Detection of preproinsulin (PPI) T-cells is further improved using dextramers under optimal staining conditions. (A) Schematic representation of tetramers and dextramers showing the number of streptavidins (typically, 6-7 for dextramers), peptide-MHC (pMHCs), and phycoerythrins per unit of reagent. pMHC to streptavidin molar ratios of 4:1 and 3:1 were used to assemble tetramers and dextramers, respectively. T-cell receptor (TCR). (B) Sorted CD8 T-cells from a HLA $\mathrm{A}^{*} 02: 01^{+}$patient with type I diabetes were stimulated with a peptide from PPI (PPI $\left.{ }_{15-24}\right)$ and assessed 2 weeks later for reactivity against the PPI peptide (100 nM) by co-incubation with TAPI-0 and detection of CD107a and TNF. (C) The T-cells were also stained with irrelevant (hTERT panel) and dextramers (lower panel) using standard (pMHC multimer alone) and optimal protocols (PKI + anti-PE Ab). The percentage of cells residing in each gate are shown. The red box indicates cells that were sorted by flow cytometry and shown in Figure 4.

(Figure 3B). Use of the optimized procedure in conjunction with pMHC dextramer increased the size of the detected population by over 10 -fold and brought it into line with the population size observed in the functional assay. While optimized dextramer staining vastly outperformed optimized tetramer staining in this case, the cells detected using the latter were fully functional. To formally prove functionality, we sorted cells that stained with optimized tetramer protocol and used them for further analysis (Figure 3C).

\section{Optimally Tetramer-Sorted PPI-Specific T-Cell Clones Do Not Stain With a Standard pMHC Tetramer Protocol}

Nearly all the cells $(>90 \%)$ in the HLA A2-PPI ${ }_{15-24}$ tetramerenriched T-cell line stained with HLA A2-PPI ${ }_{15-24}$ tetramer when the optimized protocol containing PKI and cross-linking $\mathrm{Ab}$ was used. In parallel, the standard protocol that omitted these steps stained only $35 \%$ of this T-cell line, and with a low mean fluorescence intensity (Figure 4A). Over 70\% of the cells in this T-cell line specifically responded to exogenously supplied
$\mathrm{PPI}_{15-24}$ peptide indicating that roughly half of the functional T-cells could not be stained using standard pMHC tetramer staining (Figure 4B). We next subjected this enriched T-cell line to cloning by limiting dilution. Of the $34 \mathrm{~T}$-cell clones generated, 33 were responsive to $\mathrm{PPI}_{15-24}$ peptide. All 33 peptide-responsive T-cell clones stained well with HLA A2-PPI ${ }_{15-24}$ tetramer when the optimized protocol was used but failed to stain without addition of PKI and cross-linking Ab. An example staining for one clone, GD.PPI.1, is shown in Figure 4C. These results provide further evidence that standard pMHC tetramer staining fails to detect fully functional PPI-specific T-cells. Peptide titrations (data not shown) with these T-cell clones indicated that they required at least $100 \mathrm{nM}$ exogenous $\mathrm{PPI}_{15-24}$ peptide in order to activate (Figure 4D). In order to determine whether such cells might be capable of responding to endogenously processed and presented peptide antigen we used "surrogate $\beta$-cell" K562 targets expressing both HLA A2 and PPI (42). T-cell clone GD.PPI.1 did not respond to K562 cells expressing HLA A 2 alone but activated in response to these cells when they were also transduced with PPI (Figure 4D). We conclude that standard pMHC tetramer staining can fail to detect fully functional diabetogenic T-cells 
capable of responding to endogenously expressed $\beta$-cell-specific proteins.

\section{Optimized pMHC Multimer Staining Is Compatible With Magnetic-Bead-Based Cell Isolation}

Flow cytometric sorting can be detrimental for T-cell fitness, and in some cases $>98 \%$ of sorted cells fail to expand in culture (59). We have previously used an optimized protocol for isolating rare pMHCII-responsive CD4 ${ }^{+}$T-cells incorporating a magnetic bead enrichment step (60). These beads capture pMHC multimer ${ }^{+}$ cells via anti-fluorochrome $\mathrm{Ab}$. We, therefore, reasoned that much of the improvement in T-cell recovery that we observed in our previous study (60) might have been due to stabilization of pMHC tetramer staining afforded by the anti-fluorochrome Ab-conjugated magnetic microbeads. We tested whether antiPE microbeads could enhance the ability to detect self-specific $\mathrm{T}$-cells using a T-cell clone that requires an optimized protocol
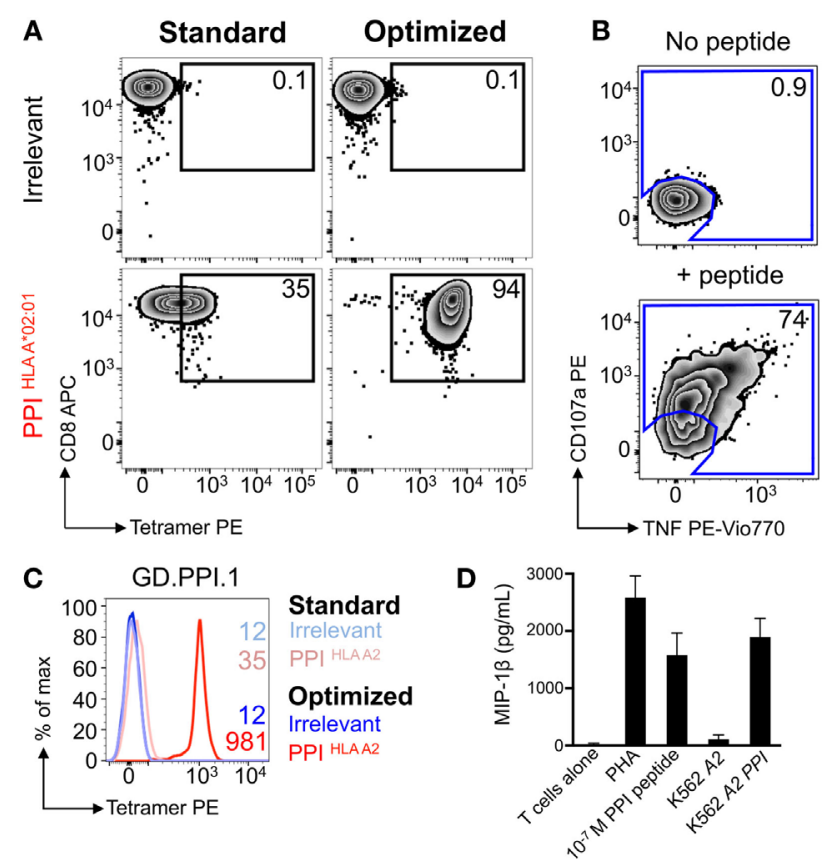

FIGURE 4 | Optimal staining with preproinsulin (PPI) tetramers allowed functional T-cells to be isolated. Peripheral blood mononuclear cells (PBMCs) from a HLA A*02:01+ patient with type I diabetes were stimulated with PPI (PPI ${ }_{15-24}$ ) peptide (Figure $\mathbf{3 A}$ ), which stained with PPI tetramer and dextramer under optimal conditions (PKI + anti-PE Ab). Tetramer+ cells were sorted by flow cytometry (Figure 3B) and expanded with PHA and irradiated allogeneic PBMCs. (A) The expanded cells were stained with irrelevant (ILAKFLHWL, hTERT $540-548$ ) and PPI tetramers using standard (tetramer alone) and optimal (as above) protocols. The percentage of cells residing in each gate is shown. (B) Reactivity of the enriched T-cells for PPI peptide was assessed by co-incubation with TAPI-0 and detection of CD107a and TNF. (C) Clone GD.PPI.1 grown from the enriched line was stained with irrelevant (hTERT) and PPI tetramers using standard and optimal protocols. The MFI of staining is shown on the histogram according to the key. (D) Overnight activation assay and MIP-1 $\beta$ enzyme-linked immunosorbent assay, with PHA as a positive control, PPI peptide $(10 \mathrm{nM})$, and K562s transduced with genes for HLA A*02:01 (A2) \pm PPI cDNA (PPI). in order to stain with cognate (HLA A2-NLSALGIFST) tetramer (protocol schematic Figure S1 in Supplementary Material). If anti-fluorochrome magnetic bead-conjugated antibodies could be used to enhance staining with pMHC tetramers, this would provide a ready means for isolating cells without subjecting them to flow cytometric based sorting (Figure 5A). As expected, selfreactive T-cell clone CR.NLS.3 failed to stain with cognate $\mathrm{pMHC}$ tetramer using standard conditions. Inclusion of PKI increased the staining intensity, which was further augmented by addition of anti-PE-conjugated magnetic beads (Figure 5B). The beads mediated a 7 - to $>11$-fold enhancement, compared to a 13 - to $>18$-fold improvement seen with soluble Ab (Figure 5B; Figure S2 in Supplementary Material), with increased bead volumes not improving the tetramer staining any further (Figure S2 in Supplementary Material). The improved effect with soluble Ab may reflect improved access and far lesser steric effects compared to bead-conjugated antibody. Overall, the protocol should allow magnetic sorting of tetramer ${ }^{+}$cells without subjecting them to the rigors of flow cytometric sorting.

In light of the fact that magnetic anti-fluorochrome $\mathrm{Ab}$ could enhance pMHC multimer staining, we next used this protocol

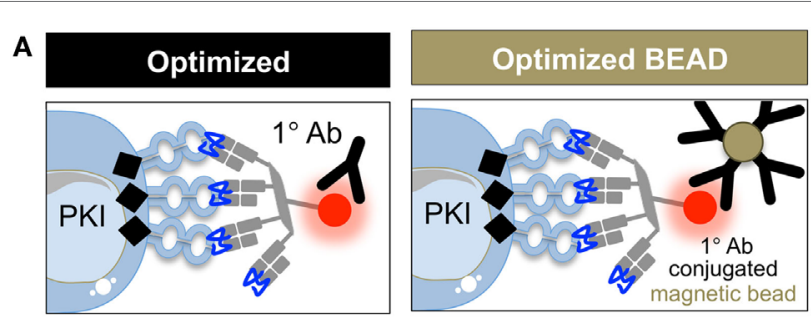

B

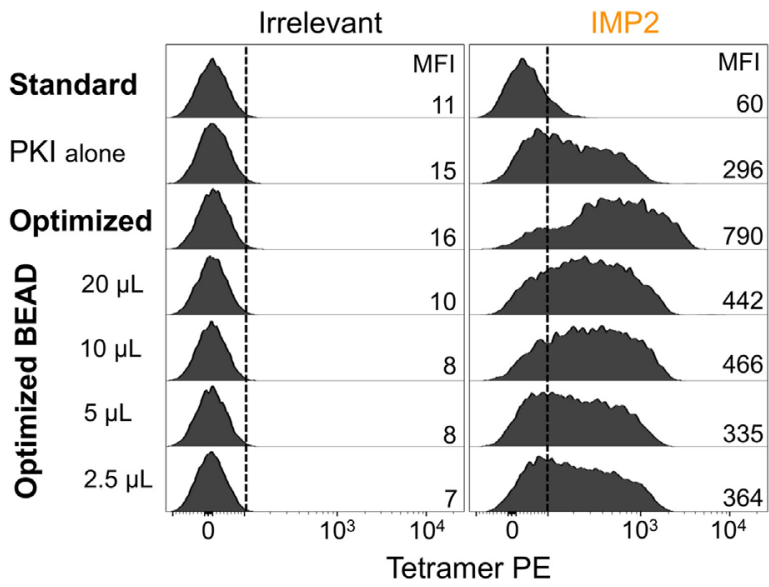

FIGURE 5 | Anti-fluorochrome magnetic microbeads enhance the staining of T-cells with tetramers. (A) The ability of a primary $\left(1^{\circ}\right)$ unconjugated anti-fluorochrome antibody (Ab) to stabilize tetramer was also tested in the form of $\mathrm{Ab}$-conjugated magnetic microbeads. (B) HLA A*02:01-restricted Melanoma reactive clone CR.NLS.3 was stained with irrelevant ILAKFLHWL

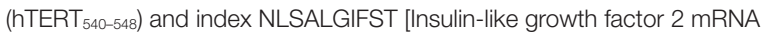
binding protein $\left.2\left(\mathrm{IMP} 2_{367-376}\right)\right]$, PE-conjugated tetramers using the conditions shown. All samples were treated with PKI apart from the standard conditions. The anti-PE magnetic microbeads were used as recommended by the manufacturer (Miltenyi Biotech), $20 \mu \mathrm{L}$ per $100 \mu \mathrm{L}$ of staining volume for up to $1 \times 10^{7}$ cells, or bead volume dilutions thereof. The MFI of staining is shown for each condition. 
to isolate and culture diabetogenic T-cells from the PBMC of another HLA A*0201 T1D patient. Patient PBMC were stained with insulin- $\beta$ chain dextramer under optimal "bead" conditions, and purified cells were expanded using PHA and allogeneic PBMCs prior to further analyses. No staining was performed on the PBMC before sorting, as sample size was limited $\left(5 \times 10^{6}\right.$ PBMCs). Limited cell number is commonplace for clinical samples due to distribution among research projects, and ethical guidelines on how much blood can be taken. The enriched line was $87 \%$ dextramer ${ }^{+}$using the optimal staining protocol, with cells also staining with dextramer under standard conditions (16\%) and with the optimized tetramer protocol (29\%) (Figure 6A). Staining was low/absent when using standard tetramer staining and suggested that very few, if any, antigen-specific T-cells would have been isolated if standard staining had initially been used. It might have been possible to isolate cells with optimal tetramer or
A

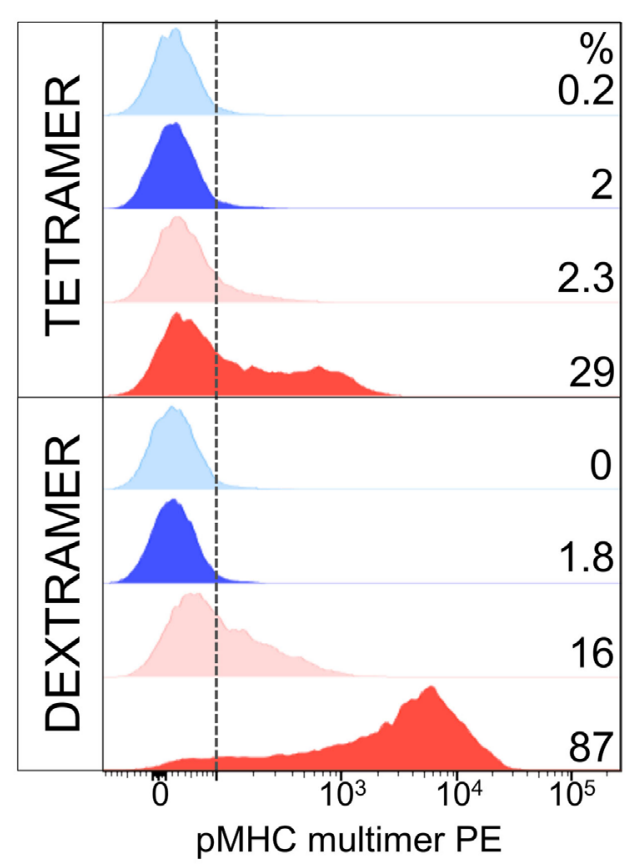

C

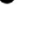

Standard
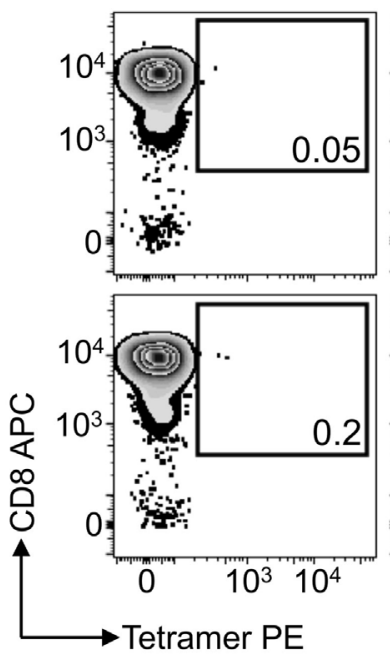

D
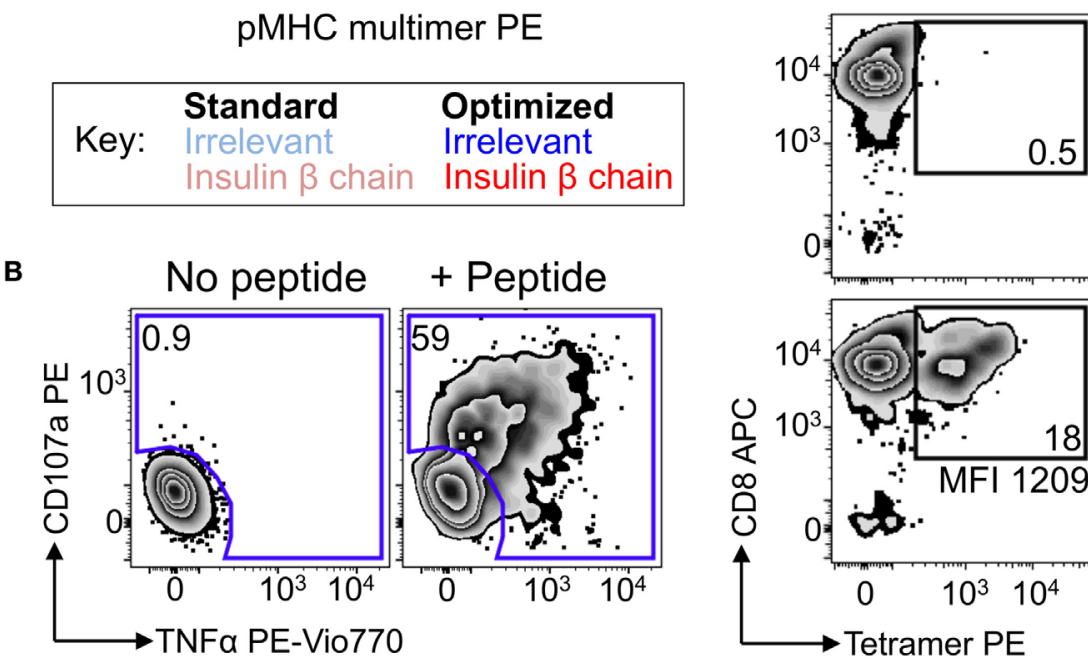

Optimized Irrelevant Insulin $\beta$ chain

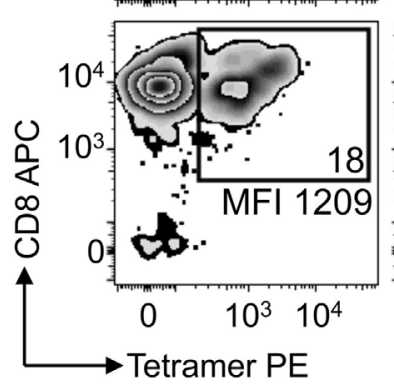

Optimized
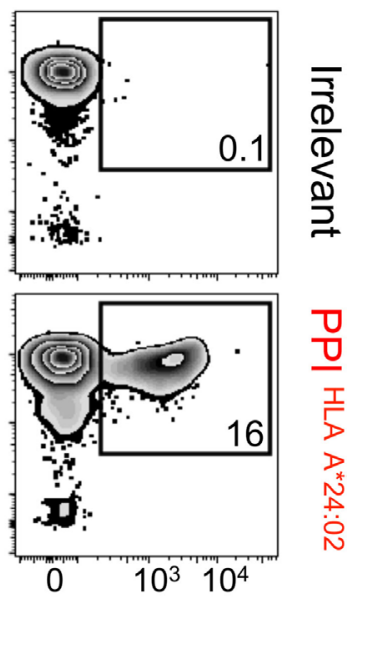

\section{0
$I$
$D$
$D$
$D$
$N$
0
$N$}

FIGURE 6 | Dextramers used with magnetic based purification allowed autoimmune T-cells to be isolated directly ex vivo. (A) Peripheral blood mononuclear cells from a HLA A*02:01+ patient with type I diabetes were treated with PKI and then stained with insulin- $\beta$ chain ${ }_{10-18}$ (HLVEALYLV) PE-conjugated dextramers. Post staining the cells were labeled with anti-PE antibody-conjugated microbeads and magnetically enriched. T-cells were grown in vitro for 3 weeks then stained with PE-conjugated insulin- $\beta$ chain tetramer and dextramers, with hTERT ${ }_{540-548}$ (ILAKFLHWL) multimers as an irrelevant control. Staining was performed under standard (multimer alone) or optimized (PKI + anti-PE Ab) conditions. The dotted line depicts the baseline for staining based on irrelevant multimers, with the percentage of cells staining above this shown for each condition. (B) The magnetically enriched T-cell line generated in A was tested for reactivity against insulin- $\beta$ chain peptide by incubation with TAPI-0 and staining for TNF and CD107a. The percentage of cells residing in each gate is shown. (C,D) $C D 8 \mathrm{~T}^{-c e l l s}$ from an $\mathrm{HLA} \mathrm{A}^{*} 02: 01^{+} \mathrm{A}^{\star} 24: 02^{+}$ type 1 diabetes patient were enriched using the same approach shown in A, using either HLA A*24:02-PPI 3 -11 (LWMRLLPLL) dextramer (C) or HLA A*02:01IGRP $_{265-273}$ (VLFGLGFAI) dextramer (D). Two weeks post expansion the cells were stained with their respective tetramers. hTERT tetramers were used as an irrelevant control. The percent of gated cells is shown and the mean fluorescence intensity for the PPI or IGRP staining displayed. 
standard dextramer protocols but the optimal "bead" dextramer approach we applied gave a combination of superior staining and potential for magnetic enrichment. The T-cell line produced in this way showed specific reactivity for the Insulin- $\beta$ chain peptide (Figure 6B) confirming that the purification process using dextramers and magnetic beads had been successful. Similarly, PPI (residues 3-11, HLA A*24:02 restricted) and IGRP (residues 265-273, HLA A*02:01 restricted)-specific T-cells were successfully enriched using dextramers and the optimal bead method for another patient. Subsequent staining of the cells with tetramers showed that PPI-specific T-cells could only be detected when the optimal protocol was used (Figure 6C). A less dramatic difference in terms of cell numbers between standard and optimized protocol was observed in case of the IGRP specific T-cells-however, the staining intensity was increased nearly fivefold in the latter case (Figure 6D). These results demonstrated that optimized pMHC multimer staining could be successfully combined with anti-fluorochrome $\mathrm{Ab}$-conjugated beads to enable isolation and culturing of antigen-specific autoimmune T-cells. We next set out to apply this technique to obtain autoimmune T-cells from ankylosing spondylitis patients.

\section{Optimal Staining and Isolation of Antigen- Specific T-Cells From Ankylosing Spondylitis Patient Samples Using HLA B`27:05 Tetramers}

Ankylosing spondylitis (AS) is a HLA $B^{\star 27: 05}$ associated autoimmune disease with characteristic inflammation of the joints and spine (61). HLA $B^{\star}$ 27:05 tetramers refolded with the RRKWRRWHL peptide (residues 400-408 from VIPR1) were used for ex vivo staining of a PBMC sample from an AS patient. There was a fivefold increase in VIPR1 tetramer staining using the optimal protocol $(0.04 \%)$ compared to the standard approach $(0.008 \%)$, with similar irrelevant tetramer staining for both conditions (Figure 7A). Using optimal "bead" staining and magnetic separation, the VIPR1 tetramer ${ }^{+}$cells were enriched to $9.7 \%$ when re-stained using the optimal protocol (Figure 7B). The same approach was used for a second AS patient (Figure 7C). Clones were obtained from both enriched lines by limiting dilution and characterized with VIPR1 tetramer. T-cell clones GD.AS69 and GD.AS2 were grown from the line shown in Figure 7B. The GD.AS69 clone needed the optimal protocol to stain with
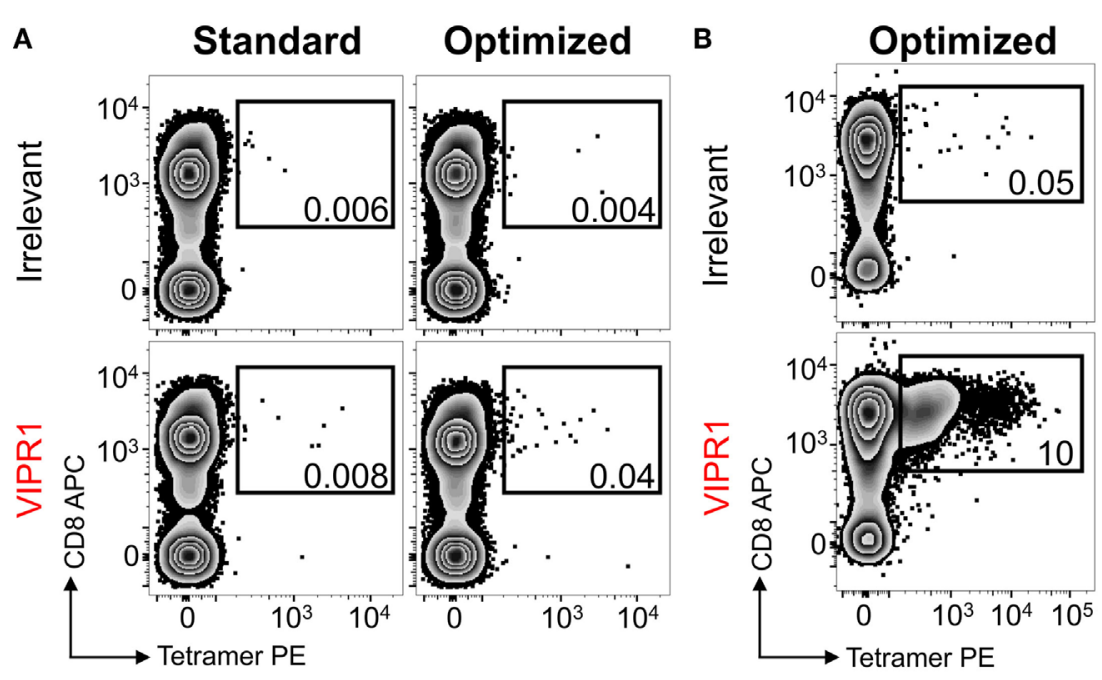

C

Standard

\section{Optimized}

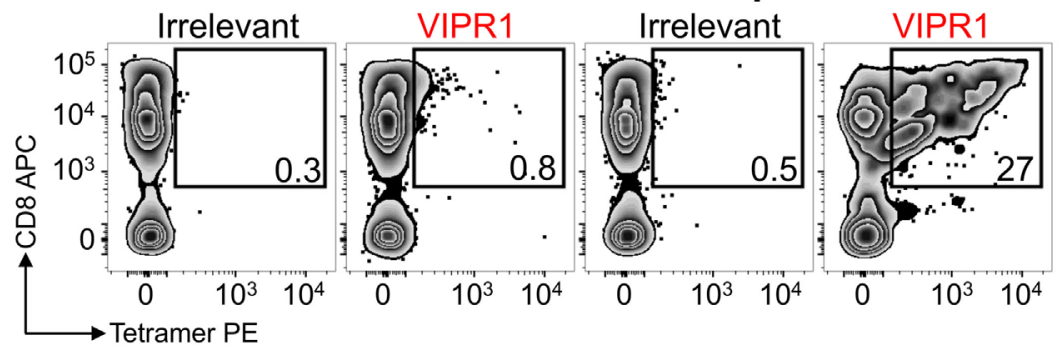

FIGURE 7 | HLA B²7:05 vasoactive intestinal polypeptide receptor 1 (VIPR1) tetramers used with optimal staining conditions allowed autoimmune T-cells to be detected and isolated from patients with ankylosing spondylitis. (A) Peripheral blood mononuclear cells (PBMCs) from a HLA B`27:05 patient with ankylosing spondylitis were stained with irrelevant (HIV p24 gag ${ }_{263-272}$; KRWILLGLNK) and VIPR1 ${ }_{400-408}$ (RRKWRRWHL) PE-conjugated tetramers directly ex vivo under standard (tetramer alone) and optimal (PKI + anti-PE Ab) conditions. (B) PBMCs for the same patient in A were PKI treated and stained with PE-conjugated VIPR1 $400-408$ tetramers then labeled with anti-PE antibody-conjugated microbeads for magnetic purification. After 3 weeks of culture, the line was stained with irrelevant (p24 gag) and VIPR1 tetramer under optimal staining conditions. (C) Using the same approach as in B from a second patient. Cells were stained 3 weeks post purification with irrelevant (HIV p24 gag 263-272 ) and VIPR1 ${ }_{400-408}$ tetramers using standard and optimal staining protocols. 
VIPR1 tetramer (Figure 8A). Conversely, clone GD.AS2 did stain under standard conditions but the optimal protocol substantially increased the intensity of staining (Figure 8A). Clone GD.Russ2, derived from the second donor, required the optimal protocol to stain with VIPR1 tetramer, similarly to GD.AS69 (Figure 8A). Clones GD.AS69 and GD.AS2 responded to exogenous VIPR peptide and were sufficiently sensitive to recognize an autologous B-cell line transduced to express the VIPR1 protein (Figure 8B). Thus, optimized pMHC multimer staining allowed successful culture and cloning of VIPR-reactive, HLA $B^{\star} 27$ :05-restricted T-cells. Two of three clones generated could not be stained with standard pMHC multimer staining protocol, and therefore, would not have been isolated without the optimized technique applied here.

\section{DISCUSSION}

\section{Standard pMHCI Tetramer Staining Fails to Detect Antigen-Specific T-Cells With Low-Affinity TCRs}

Peptide-MHC multimers are widely accepted as the "gold standard" for the detection and isolation of antigen-specific $\mathrm{T}$-cells. As these reagents rely on physical detection, cognate cells can be detected without relying on any particular effector function.
Physical detection of T-cells has some further advantages over functional detection as cells that are in the process of dividing would be unlikely, or unable, to respond by killing a target or secreting a lymphokine, and therefore, would remain undetectable. When used optimally, pMHC multimers usually detect a larger population of antigen-specific T-cells than responding cells in a functional assay. In keeping with this observation, we consistently found more antigen-specific cells with optimal pMHC multimer staining than were detected in parallel functional assays. Accordingly, throughout our dataset, the fraction of T-cells detected with optimal pMHC multimer staining was higher than that detected in functional assays (detecting CD107a and/or TNF). Conversely, standard staining protocols detected a fraction of cells that was generally smaller than that revealed by functional assay confirming that some functional T-cells were not detected. These observations are in line with tetramer staining verses functional readouts using monoclonal T-cell populations where all cells might be expected to have capacity to respond to relatively high concentrations of exogenous cognate peptide. In parallel comparisons, $99.6 \%$ of the $1 \mathrm{E} 6 \mathrm{~T}$-cell clone stained with cognate tetramer while only 27 and $20 \%$ responded by intracellular staining for TNF in response to $1 \mu \mathrm{g} / \mathrm{mL}$ of cognate peptide or target cells expressing the cognate HLA A2 and PPI target, respectively (42). Similarly, 99\% of GAD65-specific T-cell clone RK9C10 stained with pMHC tetramer while only 50.6 and
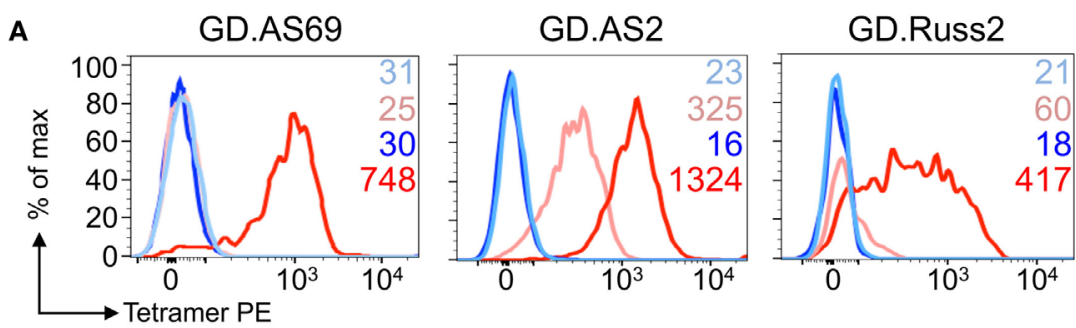

Key: Standard: Irrelevant VIPR1 Optimized: Irrelevant VIPR1

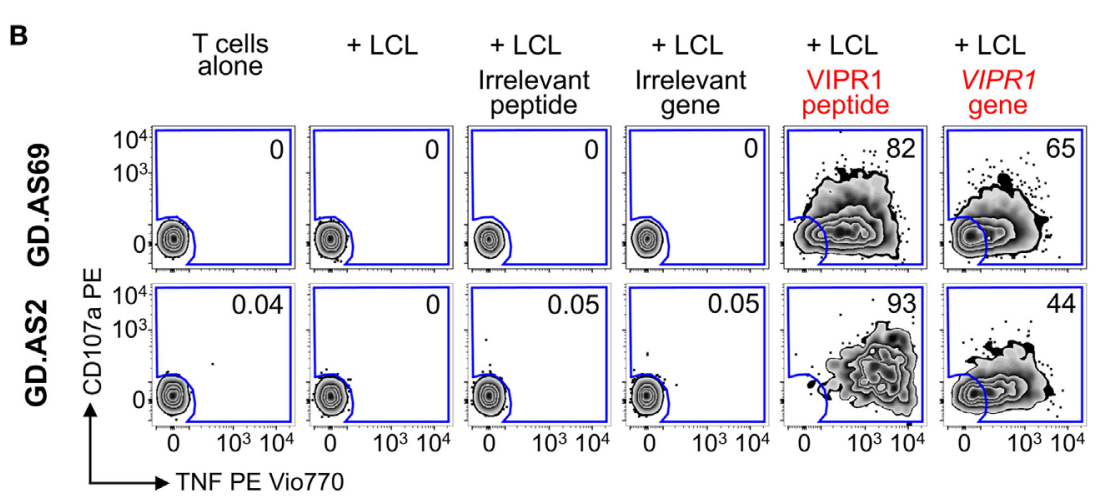

FIGURE 8 | CD8 clones isolated from an ankylosing spondylitis patient using optimal tetramer staining are fully functional. (A) CD8 T-cell clones grown from T-cell lines (Figure 7) generated following tetramer enrichment using an optimal magnetic bead protocol (Figure 5). GD.AS69, GD.AS2, and GD.Russ2 were stained with HIV p24 gag $263-272$ (KRWILLGLNK) and VIPR1 ${ }_{400-408}$ (RRKWRRWHL) PE-conjugated HLA B*27:05 tetramers, using standard (tetramer alone) and optimized $(\mathrm{PKI}+$ anti-PE Ab) protocols, according to the key. The MFI of staining is shown. (B) Functional testing of clones GD.AS69 and GD.AS2 using a TAPI-0 assay with CD107a and TNF Abs. Patient autologous lymphoblastoid cell line (LCL) was used to present HLA B`27:05 irrelevant peptide (DRASFIKNL from the $\alpha 2$ domain of collagen type $\mathrm{Vl}_{114-122}$ ) and cognate VIPR1 $1_{400-408}$ peptide (RRKWRRWHL). Autologous LCL were lentivirally transduced with genes for the $\alpha 2$ chain of collagen type $\mathrm{VI}$ (control protein) and vasoactive intestinal polypeptide receptor 1 (VIPR1) and used in the activation assay. Percentage reactivity is shown for the CD107a+ TNF+ gate. 
$62 \%$ responded by intracellular TNF and surrogate degranulation marker CD107a staining, respectively (56). We provide three further examples of parallel tetramer staining and activation of T-cell clones in Figure S3 in Supplementary Material, while all three clones exhibit $>99 \%$ tetramer staining their activation with $10 \mu \mathrm{M}$ cognate peptide or real melanoma target cells ranges from 52 to $83 \%$. Thus, up to half of cognate T-cells that express TCR and that can be stained with pMHC multimer fail to respond in effector function assay.

The original pMHC multimer, a streptavidin-based $\mathrm{pMHC}$ tetramer (18), is still the most common form in use as it can be easily manufactured in-house (as here), or acquired via the $\mathrm{NIH}$ Tetramer Core Facility (Emory) or various commercial sources. Unfortunately, the TCR-pMHC affinity threshold amenable to detection by standard pMHC tetramer staining is higher than that required for efficient T-cell activation (21). Thus, these reagents can fail to detect fully functional T-cells with low-affinity TCRs and thereby underestimate the size of antigen-specific T-cell populations. This effect can be particularly pronounced for selfreactive T-cells, or MHCII-restricted T-cells, where TCR-pMHC interactions are weaker (10). Indeed, several recent studies by different research groups have reported that, with some antigens, standard pMHC multimer staining can fail to stain the majority of antigen-specific T-cells $(23,33,62)$. It has even been suggested that this discrepancy and the prominent use of pMHC staining for T-cell detection has biased T-cell immunology toward the type of T-cells that can be readily detected with these reagents because the important, low-affinity TCRs that can dominate antigen-specific T-cell responses are ignored $(63,64)$. The aim of this study was to compare the recovery of antigen-specific, self-reactive T-cells from patient samples using standard $\mathrm{pMHC}$ staining or an optimized protocol and to compare the results to functional assays for T-cell activation.

\section{An Optimized pMHC Multimer Protocol Can Recover Autoimmune T-Cells}

We have developed a variety of "tricks" in an attempt to circumvent the problem of unsuccessful staining of T-cells bearing weak affinity TCRs using the standard procedures $(17,20)$. The simplest, and least expensive, of these improvements are the addition of PKI to prevent TCR triggering and downregulation (32) and the addition of an $\mathrm{Ab}$ (usually anti-fluorochrome) to cross-link the pMHC multimers (33). The advantages of these procedures are additive, and they can be applied with any pMHC multimer in all species tested to date for a cost of less than $\$ 0.05$ per stain. Application of this optimized procedure in this study routinely detected an average of 40.5-fold (range 1.4- to 198-fold) more antigen-specific T-cells than parallel assays in the absence of PKI and anti-fluorochrome $\mathrm{Ab}$. Whereas standard staining routinely discovered a smaller population of antigen-specific T-cells than could be detected in functional assays, the optimized protocol always detected more cells than parallel functional assays. As discussed above, the difference between the size of antigen-specific T-cell populations recovered by optimized pMHC tetramer staining and that revealed in functional assays might represent those cells that are undergoing cell division or happen to express a low level of TCR on their surface. We routinely observe that less cells respond functionally than stain with pMHC multimer even within clonal T-cells (Figure S3 in Supplementary Material). Overall, our results show that optimized protocols are substantially better at detecting self-reactive T-cells than standard protocols. The question remains whether the "optimal" protocol using pMHC dextramer $+\mathrm{PKI}+\mathrm{Ab}$ recovers all the T-cells capable of responding to a given pMHC, or whether there are functional T-cells bearing TCRs too weak to be captured using even this optimized procedure.

\section{Are Higher Order pMHC Multimers Better?}

We have been asked this question many times since we compared staining with pMHC tetramers to that with pMHC dextramers in parallel assays and found that the higher order multimers, which carry more copies of both pMHC and fluorochrome per molecule, could recover CD4 and CD8 T-cells with weaker TCRs (22). Subsequently, Davis and colleagues showed that pMHC dodecamers, which incorporate 12 pMHC per molecule, stained twofold to fivefold more murine and human CD4 and CD8 T-cells than detected in parallel assays with pMHC tetramers (23). These findings make it clear that, for T-cells with lowaffinity TCRs, higher order multimers can beat pMHC tetramers in head-to-head assays using the same conditions. However, the threshold of TCR affinity amenable to detection with pMHC tetramers with the optimal protocol used here is very low and below that found on the vast majority of cognate T-cells. We also find that an optimal staining with $\mathrm{pMHC}$ tetramer can recover cells that cannot be detected using standard pMHC dextramer protocols as currently listed on the Immudex website (March 2018). We regularly see T-cells that can be stained with optimized pMHC tetramer staining that cannot be stained by standard pMHC dextramer staining in the absence of the PKI $+\mathrm{Ab}$; this threshold is graphically depicted in Figure 1. The staining of the dextramer-sorted insulin- $\beta$ line in Figure $\mathbf{6}$ provides a good example of these sensitivities; staining of this line was greatest using dextramer $+\mathrm{PKI}+\mathrm{Ab}(87 \%)$ compared to 29,16 , and $2.3 \%$ for optimized tetramer staining, standard dextramer staining, and standard tetramer staining, respectively. Optimized pMHC tetramer staining was readily able to detect the PPI-specific 1E6 T-cell clone when it was spiked into a PBMC samples (33); this T-cell is known to bear a very weak affinity TCR $\left[K_{\mathrm{D}}>240 \mu \mathrm{M}\right.$ $(15,65)]$. Optimized pMHC tetramer staining can also recover the ILA1 T-cell clone from PBMC using the $5 \mathrm{Y}$ variant of the ILAKFLHWL hTERT-derived (41) peptide which similarly has a $K_{\mathrm{D}} \sim 250 \mu \mathrm{M}$ (33). Optimized pMHC tetramer staining with the $8 \mathrm{E}$ variant in this system, which is estimated to bind with $K_{\mathrm{D}} \sim 2 \mathrm{mM}$ (and $>500 \mu \mathrm{M}$ with certainty), did not recover the ILA1 T-cell in parallel experiments (33). The fact that optimized pMHC dextramer staining with the $8 \mathrm{E}$ variant can fully recover the ILA1 T-cell clone in parallel experiments provides some indication of where the threshold of detection for optimized pMHC tetramer and dextramer must lie. However, pMHC multimer binding thresholds are dependent on both TCR and CD8 expression levels so can vary with time for cultured cells, or if cells have recently encountered cognate antigen in vivo, so the above should only be taken as a rough estimate. In summary, 
all but T-cells bearing the very weakest of cognate TCRs can be recovered using an optimized $\mathrm{pMHC}$ tetramer protocol. Thus, any pMHC multimer with 4 or more pMHC per molecule should be sufficient for almost all purposes providing an optimized protocol including PKI and cross-linking Ab is adopted, and we believe that the advantages afforded by higher order multimers will only rarely be required.

\section{Are T-Cells With Very Low-Affinity TCRs Truly Functional?}

It is becoming increasingly clear that optimized pMHC multimer staining procedures can stain T-cells with cognate TCRs that are far weaker than were previously believed to have any possibility of being functional. Consequently, it is worth asking two questions: (1) Can extremely weak TCR interactions trigger and activate T-cells? And (2) do low-affinity TCRs make a significant contribution to immunity? These important points will be addressed below.

\section{Extremely Weak TCR Interactions Can Activate T-Cells}

The best model system we are aware of for addressing this issue is the ILA1 T-cell/TCR, which recognizes the hTERT-derived peptide ILAKFLHWL (41). The ILA1 TCR refolds reasonably well to allow biophysical and structural studies with the soluble extracellular domain (66). As described above, the $5 \mathrm{Y}$ and $8 \mathrm{E}$ variants of ILAKFLHWL bind to the ILA1 TCR with $K_{\mathrm{D}}$ S of $>240 \mu \mathrm{M}$ and $>500 \mu \mathrm{M}$, respectively (21). The $5 \mathrm{Y}$ and $8 \mathrm{E}$ variants of ILAKFLHWL act as reasonable agonists of the ILA1 T-cell; although these ligands are completely dependent on MHC interaction with the CD8 coreceptor (67). Thus, this model system suggests that extremely weak TCR interactions can activate T-cells. In the real world, the PPI peptide-specific 1E6 TCR, identified in a patient $\mathrm{T}$-cell that can kill human pancreatic $\beta$-cells (42), thus demonstrating responsiveness to natural target cells, has a TCR affinity of $>240 \mu \mathrm{M}(15,65)$. In this study, we found that optimized pMHC tetramer staining recovered less T-cells from an insulin- $\beta$ CD8 T-cell line than could be detected by functional assay (Figures 6A,B) and that standard pMHC dextramer staining only detected $35 \%$ of a PPI-specific T-cell line where $>70 \%$ of $\mathrm{T}$-cells responded to cognate peptide in a functional assay (Figure 4). The T-cells that responded to peptide but were not recovered using pMHC staining in these assays presumably express TCRs with extremely weak affinity for the cognate antigen. Based on the available evidence, we conclude that extremely weak TCR interactions can indeed activate T-cells but this does not prove that such T-cells are of biological relevance, particularly if they are competing for antigen in vivo with T-cells that have higher affinity TCRs.

\section{Low-Affinity TCRs Make a Significant Contribution to Immunity}

Our own data show that T-cells with low-affinity TCRs can function relatively poorly $(12,13,21)$. These data fit with the general picture that has emerged from classic kinetic proofreading models of TCR triggering and T-cell activation $(68,69)$. Thus, there is now a general belief that T-cells that are most sensitive to antigen will bear the highest affinity TCRs and that these T-cells will, by definition, be avid binders of soluble pMHC multimers. The flipside of this viewpoint is that T-cells with weak affinity TCRs will be insensitive to peptide antigen and will be unlikely to play a dominant immune role in vivo. Our faith in the importance of TCR affinity and the emergence of pMHC tetramers as a gold standard for T-cell detection may have been responsible for study bias which underestimates the role of low-affinity TCRs (63). In the absence of definitive proof, assumptions that staining with pMHC multimer is a surrogate of how antigen-sensitive a given T-cell might be and of how effective and important it is in vivo are precarious. As discussed below, the view that T-cells with low-affinity TCRs are relatively insignificant during regular immune responses has softened over the last 8 years with murine studies showing first that low-affinity TCR interactions generate a complete immune response during the first week of infection with Listeria monocytogenes (70) through to recent data showing that TCRs that escape negative selection and that cannot be stained with cognate $\mathrm{pMHC}$ tetramer have sufficient reactivity to cause disease in vivo (71).

\section{Evidence From Humans and Other Primates}

A recent video study that provided protocols for pMHCI staining of Simian Immunodeficiency Virus-specific CD8 T-cells in Rhesus Macaques showed that addition of $50 \mathrm{nM}$ Dasatinib enhanced staining from $0.1 \%$ of $\mathrm{CD}^{+} \mathrm{T}$-cells to $0.96 \%$ with a considerable concomitant increase in the MFI (34). Here, our demonstration that patient-derived T-cells with low-affinity TCRs can respond to relevant targets expressing endogenous antigen suggests that these cells have capacity to be relevant in vivo. Furthermore, the 1E6 TCR isolated from a T1D patient, and capable of killing HLA $A^{\star} 02: 01^{+}$pancreatic $\beta$-cells in a glucose-dependent manner (42), has a low-affinity TCR $\left(K_{\mathrm{D}}>240 \mu \mathrm{M}\right)$. Other patient-derived TCRs that see different diabetogenic epitopes also bind with $K_{\mathrm{D}}>150 \mu \mathrm{M}$ (manuscript in preparation) in line with suggestions that very weak TCRs are a common feature of autoimmune T-cells (10) (Figure 1). In accordance, a study of HLA DR-restricted responses to a type II collagen-derived peptide in a patient with relapsing polychondritis found that patient PBMC contained T-cells that could be activated by this peptide or a plate-bound form of the pMHC but could not be detected by tetramer staining with this same $\mathrm{pMHC}$; these results were confirmed using patient-derived T-cell clones and attributed to autoimmune TCR-pMHC interactions being weak (72).

We have also recently demonstrated that the dominant tumorinfiltrating lymphocyte-derived clonotypes in patient blood following successful "cure" (complete lasting remission) of Stage IV melanoma can only be detected by optimized pMHC multimer staining (59). Clones expressing these TCRs were grown in culture and shown to kill autologous tumor but were only amenable to optimized pMHC multimer staining, suggesting that they bore TCRs with low-affinity for cognate antigen. These data strongly suggest that low-affinity TCRs substantially contribute to mediating remission during successful immunotherapy. We have also made the unexpected discovery that PBMC from the majority of EBV seropositive HLA $A^{*} 02: 01^{+}$individuals contain functional CD8 T-cells specific for the immunodominant BMLF1-derived 
epitope GLCTLVAML that can only be stained with the optimized procedure described here. PBMC from one individual made a strong response to GLCTLVAML peptide but showed very poor staining with pMHC tetramer in the absence of PKI and crosslinking $\mathrm{Ab}$ (59). Optimized staining revealed a sizeable population of T-cells $\left(0.15 \%\right.$ of total $\mathrm{CD}^{+}$cells $)$that stained with high intensity. A clonal population of BMLF1-specific cells from this individual responded to $100 \mathrm{pM}$ peptide and an autologous EBV-transformed B-cell line suggesting that these cells had capacity to exhibit strong potency in vivo (59). Davis and colleagues found that $10 \mathrm{nM} \mathrm{pMHC}$ dodecamer could recover a large population of CMV-specific T-cells from PBMC (1.76\% of total T-cells); parallel staining with $10 \mathrm{nM}$ pMHC tetramer recovered a population 100 times smaller $(0.017 \%)$ (23). Similarly, $10 \mathrm{nM}$ dodecamer of the influenza A virus $\mathrm{HA}_{306-318}$ epitope HLA DR4-GGPKYVKQNTLKLAT recovered a population of cells comprising $0.92 \%$ of total T-cells compared to recovery of over fourfold less T-cells with pMHC tetramer even when used at 15 times higher concentrations (23). The authors conclude that "traditional tetramers may significantly underestimate the actual frequency of antigen-specific T-cells in the repertoire, which might be physiologically important in maintaining and mediating the effector function and homeostasis of the adaptive immune system." In summary, increasing evidence suggest that human T-cells that bear weak TCRs that cannot be detected with standard pMHC tetramer staining play an important immune role. Nevertheless, it is impossible to definitively prove that these cells are important in vivo.

\section{Evidence From Mice}

Although there is abundant recent evidence demonstrating that low-affinity TCRs can make a profound contribution to immunity, the counterview suggested in older studies is still prevalent. Unfortunately, most studies of TCR affinity and T-cell activation in mice have been undertaken in transgenic animals where all T-cells express a single, high-affinity TCR. Zehn and colleagues broke this mold by deliberately constructing a mouse expressing a TCR that barely escaped from negative selection (i.e., a TCR with affinity for self-antigen at the threshold of affinity that determines whether a T-cell is culled by negative selection or survives central tolerance mechanisms) (71). The resultant low-affinity OT3 $\mathrm{T}$-cells are below the limit for reliable detection by conventional tetramer staining. However, OT3 T-cells, developed into functional effector and memory T-cells, had sufficient reactivity to cause disease and could respond to ligands that bound with an affinity well below the affinity threshold for negative selection (71). These even weaker ligands would have almost certainly not stained OT3 T-cells with standard pMHC tetramer staining technology, yet they were capable of inducing acute activation in the periphery. This well-defined model of autoimmune $\mathrm{T}$-cells in vivo demonstrated that T-cells with extremely weak TCR-pMHC interactions, well below the threshold for pMHC multimer staining, can make a profound contribution to tissue destruction. Earlier studies, by Zehn et al., in the high-affinity OT1 transgenic model first gave hints that very weak TCR ligands could be functional and showed that such interactions were sufficient to induce initial rapid expansion of naïve T-cells to generate effector and memory cells, thereby challenging the view that strong TCR-pMHC interaction were a prerequisite of CD8 T-cell activation (70). Even the V4 variant of the OT1 cognate OVAderived SIINFEKL peptide expanded OT1 cells in vivo when delivered in recombinant L. monocytogenes (70). Remarkably, the OT1 TCR binds to the V4 variant with a $K_{\mathrm{D}}$ of $>1 \mathrm{mM}$ by SPR (4); yet, this ligand could induce similar proliferation to the wild-type OVA ligand over 6-7 division cycles and produce cells with a similar effector phenotype 1 week after infection despite having an affinity well below the threshold for negative selection (70). The only major difference observed between a strong TCR stimulus and an extremely weak stimulus occurred at later time points and affected the length of the expansion period and the concomitant burst size (i.e., responses induced by very weak TCR ligands were curtailed). Despite the difference in burst size, the primed T-cells developed into memory cells that were comparable after adoptive transfer and challenge with L. monocytogenes expressing wild-type SIINFEKL sequence indicating that recall expansion was independent of the priming antigen stimuli (70).

Despite the compelling data described above, showing that low-affinity TCR-pMHC interactions can be extremely relevant in vivo, these transgenic models may bear little relevance to the real-world situation where polyclonal T-cell populations compete with each other for limited antigen. Evidence that TCR affinity may set the basal activity of T-cells by regulating the expression of restricting phosphatases such as SHP-1 (73), suggests that any preference for high-affinity TCRs could be offset by counterbalancing mechanisms that "level the playing field" and allow weak affinity TCRs to compete with their more avid counterparts. Recent data from Evavold and colleagues examining six different polyclonal CD4 T-cell responses in mice challenges the notion that T-cells with high-affinity TCRs, which are amenable to detection with standard pMHC tetramer technology, are the major responders during primary immune responses (64). Instead, these data show that T-cells that stain by standard tetramer technology comprise just $5-30 \%$ of the total antigen-specific naïve murine T-cell repertoire. A study of TCR diversity and T-cell sensitivity in humanized HLA DR4 mice immunized with the human cartilage gp-39263-275 epitope uncovered great variability in the ability of HLA DR4-gp-39 ${ }_{263-275}$ tetramers to stain cognate hybridomas. Over $30 \%$ of the hybridomas that responded to cognate antigen could not be tetramer stained leading the authors to suggest that "immune responses that are dominated by relatively low-affinity TCR interactions, such as those that may occur in autoimmune disease, will be difficult to detect using standard tetramer techniques" (74). Mass cytometry (CyTOF) experiments using 5C.C7 T-cells which bear a low-affinity TCR (75) support conclusions that pMHC tetramers fail to detect the majority of antigen-specific T-cells by showing that that a major population of tetramer-negative T-cells that only stained with higher order dodecamer, exhibited equal functionality to T-cells that stained with tetramer. Additional studies from the Evavold laboratory have demonstrated that pMHCII tetramer staining underestimated the $\mathrm{H} 2-\mathrm{IA}^{\mathrm{b}}$-restricted $\mathrm{CD}^{+}$T-cell population specific for lymphocytic choriomeningitis virus glycoprotein $61-80$ by fourfold and the $\mathrm{H} 2-\mathrm{IA}^{\mathrm{b}}$-restricted population specific for myelin oligodendrocyte glycoprotein ${ }_{35-55}$ by eightfold (62). In summary, the most recent in vivo studies lend full support 
to the notion that completely functional and important T-cell responses can remain "below the radar" when it comes to detection by the "gold standard" of pMHC tetramer staining.

\section{Optimized pMHC Multimer Staining Is Compatible With Bead-Based Magnetic Sorting}

The generation of autoimmune T-cells lines for this study greatly benefited from our discovery that anti-PE Ab-conjugated to magnetic beads improved pMHC multimer staining in much the same way as we have demonstrated for soluble anti-fluorochrome antibodies (33). This fortuitous effect then allowed magnetic sorting and culturing of T-cells that had TCRs that were below the threshold for staining by standard pMHC tetramer technology. Curiously, we previously used a technique involving such a magnetic bead step for the detection of antiviral CD4 T-cells (60). This technique appears to have become widely adopted for the characterization of CD4 T cells by pMHCII tetramers although most studies have not shown staining with and without the inclusion of beads, meaning that it is not possible to compare the intensity of staining generated with and without bead inclusion. Nevertheless, early studies using magnetic bead enrichment did show staining of samples before and after bead enrichment. Revisitation of these data in light of our discovery that antifluorochrome antibody-conjugated magnetic beads can stabilize pMHC multimer staining is revealing. A study of CD4 T-cells in nonobese diabetic mice used two different pMHCII tetramers to stain samples from peptide immunized mice before and after bead enrichment (76). Throughout this study, it is evident that the cells recovered with these reagents after enrichment with anti-PE magnetic beads exhibited a higher MFI than parallel samples without the enrichment (76). Magnetic bead enrichment was also used for the analysis of CD4 T-cells specific for the Hepatitis $\mathrm{C}$ virus directly ex vivo in patient PBMC (77). The inclusion of the magnetic bead step substantially aided the recovery of T-cells. Reanalysis of these data also shows that cells that underwent the procedure with anti-PE magnetic beads stained with higher MFI than staining without these beads (77). Presumably, the beads acted to stabilize the pMHC during final washing steps and flow cytometry as we have demonstrated for soluble anti-PE Ab (33). Our discovery in this study that anti-PE magnetic beads improve the staining of T-cells with low-affinity TCRs now suggests that part of the improved staining researchers observed over a decade ago was due to the effect we describe here. Indeed, had the anti$\mathrm{PE}$ beads been added earlier in the protocol, it is likely that the enhancement effect would have been even more pronounced. The inclusion of anti-fluorochrome magnetic beads also improved the MFI of staining in a further study from the Klenerman laboratory that used HLA-DR-HA $\mathrm{H}_{306-318}$ to stain PBMC directly ex vivo (78). Anti-fluorochrome magnetic beads have also had a positive effect on the recovery of CD8 T-cells with pMHC tetramers (79). Indeed, close scrutiny of these data from Barnes et al. (79) show that inclusion of the beads enhanced the MFI of pMHC tetramer staining and cleaned up the "tail" of tetramer ${ }^{\text {low }}$ cells to give clean populations of CD8 T-cells specific for EBV, parvovirus, and CMV. Although there is improvement of pMHC multimer staining with cross-linking Ab beads regardless of the TCR affinity, this effect is likely to be greatest when the TCR affinity is low and the TCRpMHC dwell time is short (33). The ability to stain, magnetically sort, and successfully culture T-cells with low-affinity TCRs as we have done here should aid future study of such cells.

\section{Summary}

Mounting evidence now challenges the view that only T-cells with relatively high-affinity TCRs play a prominent role in immunity. This is especially true for self-antigens where T-cells with the strongest TCRs are eliminated by central and peripheral tolerance mechanisms. Anticancer and autoimmune TCRs can bind to their cognate pMHC with very low affinities that often fall below the threshold compliant with standard pMHC multimer staining. The inexpensive and easily applied optimization methodology we describe here enables recovery of fully functional, self-reactive T-cells with extremely low TCR affinities. It remains to be seen whether the lower TCR-pMHC affinity threshold that can be detected by the optimized pMHC multimer technology is sufficient to encapsulate all $\mathrm{T}$-cells that are capable of mounting a functional response to antigen. Nevertheless, we strongly recommend that researchers apply these techniques, and where possible also assay T-cell function, to avoid underestimating the size of antigen-specific T-cell populations and the diversity of antigen-specific TCRs.

\section{ETHICS STATEMENT}

Cryopreserved PBMCs from patients with T1D were obtained with the approval of a national research ethics committee and informed consent was obtained from all participants. Ankylosing spondylitis patients were recruited locally from clinic (Cardiff Regional Experimental Arthritis Treatment and Evaluation Centre) and anonymized whole blood used for preparation of PBMCs. Patients gave informed consent in accordance with Research Ethics Committee for Wales (12/WA/0045). PBMC were obtained from a further HLA $B^{\star} 2705$ ankylosing spondylitis patient diagnosed at the Institute of Rheumatology, Russian Academy of Medical Sciences, Moscow, Russia, in accordance with modified New York criteria. This patient gave written informed consent prior to enrolling in the study. The study was approved by the local ethical committee of Pirogov Russian National Research Medical University, Moscow, Russia.

\section{AUTHOR CONTRIBUTIONS}

GD, EZ, CR, AW, LY, ML, SW, and MA performed experiments, analyzed data, and critiqued the manuscript. DC, MP, and EC provided samples and patient data and critiqued the manuscript. GD and AS conceived and directed the project and wrote the manuscript. All authors contributed to manuscript revision, read, and approved the submitted version.

\section{ACKNOWLEDGMENTS}

The authors would like to thank the Central Biotechnology Services (CBS) of Cardiff University (Wales, UK), namely Catherine Naseriyan for sorting T-cells on the FACS Aria. 


\section{FUNDING}

AS is a Wellcome Trust Senior Investigator (WT100327MA). This award funded GD, EZ, and MA. CR was supported by a Ph.D. studentship from Tenovus Cancer Care, AW was supported by the Welsh Government Sêr Cymru National Research Network. SW was supported by a Ph.D. studentship from the Medical Research Council UK. ML was supported by the Wellcome Institutional

\section{REFERENCES}

1. Bridgeman JS, Sewell AK, Miles JJ, Price DA, Cole DK. Structural and biophysical determinants of alphabeta T-cell antigen recognition. Immunology (2012) 135(1):9-18. doi:10.1111/j.1365-2567.2011.03515.x

2. Cole DK, Laugel B, Clement M, Price DA, Wooldridge L, Sewell AK. The molecular determinants of CD8 co-receptor function. Immunology (2012) 137(2):139-48. doi:10.1111/j.1365-2567.2012.03625.x

3. Rudolph MG, Stanfield RL, Wilson IA. How TCRs bind MHCs, peptides, and coreceptors. Annu Rev Immunol (2006) 24:419-66. doi:10.1146/annurev. immunol.23.021704.115658

4. Stepanek O, Prabhakar AS, Osswald C, King CG, Bulek A, Naeher D, et al. Coreceptor scanning by the $\mathrm{T}$ cell receptor provides a mechanism for $\mathrm{T}$ cell tolerance. Cell (2014) 159(2):333-45. doi:10.1016/j.cell.2014.08.042

5. Van Laethem F, Sarafova SD, Park JH, Tai X, Pobezinsky L, Guinter TI, et al. Deletion of CD4 and CD8 coreceptors permits generation of alphabetaT cells that recognize antigens independently of the MHC. Immunity (2007) 27(5): 735-50. doi:10.1016/j.immuni.2007.10.007

6. Van Laethem F, Tikhonova AN, Pobezinsky LA, Tai X, Kimura MY, Le Saout C, et al. Lck availability during thymic selection determines the recognition specificity of the T cell repertoire. Cell (2013) 154(6):1326-41. doi:10.1016/j. cell.2013.08.009

7. Van Laethem F, Tikhonova AN, Singer A. MHC restriction is imposed on a diverse $\mathrm{T}$ cell receptor repertoire by $\mathrm{CD} 4$ and $\mathrm{CD} 8$ co-receptors during thymic selection. Trends Immunol (2012) 33(9):437-41. doi:10.1016/j.it.2012. 05.006

8. Xing Y, Hogquist KA. T-cell tolerance: central and peripheral. Cold Spring Harb Perspect Biol (2012) 4(6). doi:10.1101/cshperspect.a006957

9. Aleksic M, Liddy N, Molloy PE, Pumphrey N, Vuidepot A, Chang KM, et al. Different affinity windows for virus and cancer-specific T-cell receptors: implications for therapeutic strategies. Eur J Immunol (2012) 42(12):3174-9. doi:10.1002/eji.201242606

10. Cole DK, Pumphrey NJ, Boulter JM, Sami M, Bell JI, Gostick E, et al. Human TCR-binding affinity is governed by MHC class restriction. J Immunol (2007) 178(9):5727-34. doi:10.4049/jimmunol.178.9.5727

11. Cole DK, Fuller A, Dolton G, Zervoudi E, Legut M, Miles K, et al. Dual molecular mechanisms govern escape at immunodominant HLA A2-restricted HIV epitope. Front Immunol (2017) 8:1503. doi:10.3389/fimmu.2017.01503

12. Tan MP, Gerry AB, Brewer JE, Melchiori L, Bridgeman JS, Bennett AD, et al. $\mathrm{T}$ cell receptor binding affinity governs the functional profile of cancer-specific CD8+ T cells. Clin Exp Immunol (2015) 180(2):255-70. doi:10.1111/cei.12570

13. Tan MP, Dolton GM, Gerry AB, Brewer JE, Bennett AD, Pumphrey NJ, et al. Human leucocyte antigen class I-redirected anti-tumour CD4(+) T cells require a higher $\mathrm{T}$ cell receptor binding affinity for optimal activity than CD8(+) T cells. Clin Exp Immunol (2017) 187(1):124-37. doi:10.1111/cei.12828

14. Valitutti S, Muller S, Cella M, Padovan E, Lanzavecchia A. Serial triggering of many T-cell receptors by a few peptide-MHC complexes. Nature (1995) 375(6527):148-51. doi:10.1038/375148a0

15. Bulek AM, Cole DK, Skowera A, Dolton G, Gras S, Madura F, et al. Structural basis for the killing of human beta cells by CD8(+) T cells in type 1 diabetes. Nat Immunol (2012) 13(3):283-9. doi:10.1038/ni.2206

16. Chen JL, Stewart-Jones G, Bossi G, Lissin NM, Wooldridge L, Choi EM, et al. Structural and kinetic basis for heightened immunogenicity of $\mathrm{T}$ cell vaccines. J Exp Med (2005) 201(8):1243-55. doi:10.1084/jem.20042323

17. Wooldridge L, Lissina A, Cole DK, van den Berg HA, Price DA, Sewell AK. Tricks with tetramers: how to get the most from multimeric peptide-MHC. Immunology (2009) 126(2):147-64. doi:10.1111/j.1365-2567.2008.02848.x
Strategic Support Fund to Cardiff University College of Biomedical and Life Sciences.

\section{SUPPLEMENTARY MATERIAL}

The Supplementary Material for this article can be found online at https://www.frontiersin.org/articles/10.3389/fimmu.2018.01378/ full\#supplementary-material.

18. Altman JD, Moss PA, Goulder PJ, Barouch DH, McHeyzer-Williams MG, Bell JI, et al. Phenotypic analysis of antigen-specific T lymphocytes. Science (1996) 274(5284):94-6. doi:10.1126/science.274.5284.94

19. Doherty PC. The tetramer transformation. J Immunol (2011) 187(1):5-6. doi:10.4049/jimmunol.1101297

20. Dolton G, Tungatt K, Lloyd A, Bianchi V, Theaker SM, Trimby A, et al. More tricks with tetramers: a practical guide to staining $\mathrm{T}$ cells with peptide-MHC multimers. Immunology (2015) 146(1):11-22. doi:10.1111/imm.12499

21. Laugel B, van den Berg HA, Gostick E, Cole DK, Wooldridge L, Boulter J, et al. Different $\mathrm{T}$ cell receptor affinity thresholds and CD8 coreceptor dependence govern cytotoxic $\mathrm{T}$ lymphocyte activation and tetramer binding properties. J Biol Chem (2007) 282(33):23799-810. doi:10.1074/jbc.M700976200

22. Dolton G, Lissina A, Skowera A, Ladell K, Tungatt K, Jones E, et al. Comparison of peptide-major histocompatibility complex tetramers and dextramers for the identification of antigen-specific T cells. Clin Exp Immunol (2014) 177(1):47-63. doi:10.1111/cei.12339

23. Huang J, Zeng X, Sigal N, Lund PJ, Su LF, Huang H, et al. Detection, phenotyping, and quantification of antigen-specific T cells using a peptide-MHC dodecamer. Proc Natl Acad Sci U S A (2016) 113(13):E1890-7. doi:10.1073/ pnas. 1602488113

24. Clement M, Ladell K, Ekeruche-Makinde J, Miles JJ, Edwards ES, Dolton G et al. Anti-CD8 antibodies can trigger CD8+ T cell effector function in the absence of TCR engagement and improve peptide-MHCI tetramer staining. J Immunol (2011) 187(2):654-63. doi:10.4049/jimmunol.1003941

25. Wooldridge L, Hutchinson SL, Choi EM, Lissina A, Jones E, Mirza F, et al. Anti-CD8 antibodies can inhibit or enhance peptide-MHC class I (pMHCI) multimer binding: this is paralleled by their effects on CTL activation and occurs in the absence of an interaction between pMHCI and CD8 on the cell surface. J Immunol (2003) 171(12):6650-60. doi:10.4049/jimmunol.171.12.6650

26. Wooldridge L, Scriba TJ, Milicic A, Laugel B, Gostick E, Price DA, et al. Anticoreceptor antibodies profoundly affect staining with peptide-MHC class I and class II tetramers. Eur J Immunol (2006) 36(7):1847-55. doi:10.1002/eji. 200635886

27. Daniels MA, Jameson SC. Critical role for CD8 in T cell receptor binding and activation by peptide/major histocompatibility complex multimers. J Exp Med (2000) 191(2):335-46. doi:10.1084/jem.191.2.335

28. Melenhorst JJ, Scheinberg P, Chattopadhyay PK, Lissina A, Gostick E, Cole DK, et al. Detection of low avidity CD8(+) T cell populations with coreceptor-enhanced peptide-major histocompatibility complex class I tetramers. J Immunol Methods (2008) 338(1-2):31-9. doi:10.1016/j.jim.2008. 07.008

29. Wooldridge L, Lissina A, Vernazza J, Gostick E, Laugel B, Hutchinson SL, et al. Enhanced immunogenicity of CTL antigens through mutation of the CD8 binding MHC class I invariant region. Eur J Immunol (2007) 37(5):1323-33. doi:10.1002/eji.200636765

30. Cole DK, Gallagher K, Lemercier B, Holland CJ, Junaid S, Hindley JP, et al. Modification of the carboxy-terminal flanking region of a universal influenza epitope alters CD4(+) T-cell repertoire selection. Nat Commun (2012) 3:665. doi:10.1038/ncomms1665

31. Holland CJ, Dolton G, Scurr M, Ladell K, Schauenburg AJ, Miners K, et al. Enhanced detection of antigen-specific CD4+ T cells using altered peptide flanking residue peptide-MHC class II multimers. J Immunol (2015) 195(12):5827-36. doi:10.4049/jimmunol.1402787

32. Lissina A, Ladell K, Skowera A, Clement M, Edwards E, Seggewiss R, et al. Protein kinase inhibitors substantially improve the physical detection of T-cells with peptide-MHC tetramers. J Immunol Methods (2009) 340(1):11-24. doi:10.1016/j.jim.2008.09.014 
33. Tungatt K, Bianchi V, Crowther MD, Powell WE, Schauenburg AJ, Trimby A, et al. Antibody stabilization of peptide-MHC multimers reveals functional T cells bearing extremely low-affinity TCRs. J Immunol (2015) 194(1):463-74. doi:10.4049/jimmunol.1401785

34. Gonzalez-Nieto L, Domingues A, Ricciardi M, Gutman MJ, Maxwell HS, Pedreno-Lopez N, et al. Analysis of simian immunodeficiency virus-specific CD8+ T-cells in Rhesus Macaques by peptide-MHC-I tetramer staining. J Vis $\operatorname{Exp}$ (2016) (118). doi:10.3791/54881

35. Tungatt K, Dolton G, Morgan SB, Attaf M, Fuller A, Whalley T, et al. Induction of influenza-specific local CD8 T-cells in the respiratory tract after aerosol delivery of vaccine antigen or virus in the Babraham inbred pig. PLoS Pathog (2018) 14(5):e1007017. doi:10.1371/journal.ppat.1007017

36. van der Linden S, Valkenburg HA, Cats A. Evaluation of diagnostic criteria for ankylosing spondylitis. A proposal for modification of the New York criteria. Arthritis Rheum (1984) 27(4):361-8. doi:10.1002/art.1780270401

37. Britanova OV, Bochkova AG, Staroverov DB, Fedorenko DA, Bolotin DA, Mamedov IZ, et al. First autologous hematopoietic SCT for ankylosing spondylitis: a case report and clues to understanding the therapy. Bone Marrow Transplant (2012) 47(11):1479-81. doi:10.1038/bmt.2012.44

38. Mamedov IZ, Britanova OV, Bolotin DA, Chkalina AV, Staroverov DB, Zvyagin IV, et al. Quantitative tracking of T cell clones after haematopoietic stem cell transplantation. EMBO Mol Med (2011) 3(4):201-7. doi:10.1002/ emmm.201100129

39. Mamedov IZ, Britanova OV, Chkalina AV, Staroverov DB, Amosova AL, Mishin AS, et al. Individual characterization of stably expanded T cell clones in ankylosing spondylitis patients. Autoimmunity (2009) 42(6):525-36. doi:10.1080/08916930902960362

40. Diamond DJ, York J, Sun JY, Wright CL, Forman SJ. Development of a candidate $\mathrm{HLA} \mathrm{A}^{\star} 0201$ restricted peptide-based vaccine against human cytomegalovirus infection. Blood (1997) 90(5):1751-67.

41. Purbhoo MA, Li Y, Sutton DH, Brewer JE, Gostick E, Bossi G, et al. The HLA $\mathrm{A}^{*}$ 0201-restricted hTERT(540-548) peptide is not detected on tumor cells by a CTL clone or a high-affinity T-cell receptor. Mol Cancer Ther (2007) 6(7):2081-91. doi:10.1158/1535-7163.MCT-07-0092

42. Skowera A, Ellis RJ, Varela-Calvino R, Arif S, Huang GC, Van-Krinks C, et al. CTLs are targeted to kill beta cells in patients with type 1 diabetes through recognition of a glucose-regulated preproinsulin epitope. J Clin Invest (2008) 118(10):3390-402. doi:10.1172/JCI35449

43. Panina-Bordignon P, Lang R, van Endert PM, Benazzi E, Felix AM, Pastore RM, et al. Cytotoxic $\mathrm{T}$ cells specific for glutamic acid decarboxylase in autoimmune diabetes. J Exp Med (1995) 181(5):1923-7. doi:10.1084/jem.181.5.1923

44. Han B, Serra P, Amrani A, Yamanouchi J, Maree AF, Edelstein-Keshet L, et al. Prevention of diabetes by manipulation of anti-IGRP autoimmunity: high efficiency of a low-affinity peptide. Nat Med (2005) 11(6):645-52. doi:10.1038/ nm1250

45. Takahashi K, Honeyman MC, Harrison LC. Cytotoxic T cells to an epitope in the islet autoantigen IA-2 are not disease-specific. Clin Immunol (2001) 99(3):360-4. doi:10.1006/clim.2001.5031

46. Chang L, Kjer-Nielsen L, Flynn S, Brooks AG, Mannering SI, Honeyman MC, et al. Novel strategy for identification of candidate cytotoxic T-cell epitopes from human preproinsulin. Tissue Antigens (2003) 62(5):408-17. doi:10.1034/ j.1399-0039.2003.00122.x

47. Kronenberg D, Knight RR, Estorninho M, Ellis RJ, Kester MG, de Ru A, et al. Circulating preproinsulin signal peptide-specific CD8 T cells restricted by the susceptibility molecule HLA-A24 are expanded at onset of type 1 diabetes and kill beta-cells. Diabetes (2012) 61(7):1752-9. doi:10.2337/db11-1520

48. Buseyne F, Blanche S, Schmitt D, Griscelli C, Riviere Y. Detection of HIVspecific cell-mediated cytotoxicity in the peripheral blood from infected children. J Immunol (1993) 150(8 Pt 1):3569-81.

49. Fiorillo MT, Maragno M, Butler R, Dupuis ML, Sorrentino R. CD8(+) T-cell autoreactivity to an HLA-B27-restricted self-epitope correlates with ankylosing spondylitis. J Clin Invest (2000) 106(1):47-53. doi:10.1172/JCI9295

50. Atagunduz P, Appel H, Kuon W, Wu P, Thiel A, Kloetzel PM, et al. HLA-B27restricted CD8+ T cell response to cartilage-derived self peptides in ankylosing spondylitis. Arthritis Rheum (2005) 52(3):892-901. doi:10.1002/art.20948

51. Nunes CT, Miners KL, Dolton G, Pepper C, Fegan C, Mason MD, et al. A novel tumor antigen derived from enhanced degradation of bax protein in human cancers. Cancer Res (2011) 71(16):5435-44. doi:10.1158/0008-5472. CAN-11-0393
52. Legut M, Dolton G, Mian AA, Ottmann OG, Sewell AK. CRISPR-mediated TCR replacement generates superior anticancer transgenic T cells. Blood (2018) 131(3):311-22. doi:10.1182/blood-2017-05-787598

53. Laugel B, Boulter JM, Lissin N, Vuidepot A, Li Y, Gostick E, et al. Design of soluble recombinant $\mathrm{T}$ cell receptors for antigen targeting and $\mathrm{T}$ cell inhibition. J Biol Chem (2005) 280(3):1882-92. doi:10.1074/jbc.M409427200

54. Haney D, Quigley MF, Asher TE, Ambrozak DR, Gostick E, Price DA, et al. Isolation of viable antigen-specific CD8+ T cells based on membrane-bound tumor necrosis factor (TNF)-alpha expression. J Immunol Methods (2011) 369(1-2):33-41. doi:10.1016/j.jim.2011.04.003

55. Nejentsev S, Howson JM, Walker NM, Szeszko J, Field SF, Stevens HE, et al. Localization of type 1 diabetes susceptibility to the MHC class I genes HLA-B and HLA-A. Nature (2007) 450(7171):887-92. doi:10.1038/nature06406

56. Knight RR, Dolton G, Kronenberg-Versteeg D, Eichmann M, Zhao M, Huang GC, et al. A distinct immunogenic region of glutamic acid decarboxylase 65 is naturally processed and presented by human islet cells to cytotoxic CD8 T cells. Clin Exp Immunol (2015) 179(1):100-7. doi:10.1111/cei.12436

57. Pinkse GG, Tysma OH, Bergen CA, Kester MG, Ossendorp F, van Veelen PA, et al. Autoreactive CD8 T cells associated with beta cell destruction in type 1 diabetes. Proc Natl Acad Sci U S A (2005) 102(51):18425-30. doi:10.1073/ pnas. 0508621102

58. Betts MR, Brenchley JM, Price DA, De Rosa SC, Douek DC, Roederer M, et al. Sensitive and viable identification of antigen-specific CD8+ T cells by a flow cytometric assay for degranulation. JImmunol Methods (2003) 281(1-2):65-78. doi:10.1016/S0022-1759(03)00265-5

59. Rius C, Attaf M, Tungatt K, Bianchi V, Legut M, Bovay A, et al. Peptide-MHC class I tetramers can fail to detect relevant functional $\mathrm{T}$ cell clonotypes and underestimate antigen-reactive T cell populations. J Immunol (2018) 200(7):2263-79. doi:10.4049/jimmunol.1700242

60. Scriba TJ, Purbhoo M, Day CL, Robinson N, Fidler S, Fox J, et al. Ultrasensitive detection and phenotyping of CD4+ T cells with optimized HLA class II tetramer staining. J Immunol (2005) 175(10):6334-43. doi:10.4049/jimmunol. 175.10 .6334

61. Ranganathan V, Gracey E, Brown MA, Inman RD, Haroon N. Pathogenesis of ankylosing spondylitis - recent advances and future directions. Nat Rev Rheumatol (2017) 13(6):359-67. doi:10.1038/nrrheum.2017.56

62. Sabatino JJ Jr, Huang J, Zhu C, Evavold BD. High prevalence of low affinity peptide-MHC II tetramer-negative effectors during polyclonal CD4+ T cell responses. J Exp Med (2011) 208(1):81-90. doi:10.1084/jem.20101574

63. Martinez RJ, Evavold BD. Lower affinity $\mathrm{T}$ cells are critical components and active participants of the immune response. Front Immunol (2015) 6:468 doi:10.3389/fimmu.2015.00468

64. Martinez RJ, Andargachew R, Martinez HA, Evavold BD. Low-affinity CD4+ $\mathrm{T}$ cells are major responders in the primary immune response. Nat Commun (2016) 7:13848. doi:10.1038/ncomms13848

65. Cole DK, Bulek AM, Dolton G, Schauenberg AJ, Szomolay B, Rittase W, et al. Hotspot autoimmune $\mathrm{T}$ cell receptor binding underlies pathogen and insulin peptide cross-reactivity. J Clin Invest (2016) 126(6):2191-204. doi:10.1172/ JCI85679

66. Cole DK, van den Berg HA, Lloyd A, Crowther MD, Beck K, EkerucheMakinde J, et al. Structural mechanism underpinning cross-reactivity of a CD8+ T-cell clone that recognizes a peptide derived from human telomerase reverse transcriptase. J Biol Chem (2017) 292(3):802-13. doi:10.1074/jbc. M116.741603

67. Wooldridge L, Laugel B, Ekeruche J, Clement M, van den Berg HA, Price DA, et al. CD8 controls T cell cross-reactivity. J Immunol (2010) 185(8):4625-32. doi:10.4049/jimmunol.1001480

68. McKeithan TW. Kinetic proofreading in T-cell receptor signal transduction. Proc Natl Acad Sci U S A (1995) 92(11):5042-6. doi:10.1073/pnas.92.11.5042

69. Rabinowitz JD, Beeson C, Lyons DS, Davis MM, McConnell HM. Kinetic discrimination in T-cell activation. Proc Natl Acad Sci U S A (1996) 93(4):1401-5. doi:10.1073/pnas.93.4.1401

70. Zehn D, Lee SY, Bevan MJ. Complete but curtailed T-cell response to very low-affinity antigen. Nature (2009) 458(7235):211-4. doi:10.1038/nature07657

71. Enouz S, Carrie L, Merkler D, Bevan MJ, Zehn D. Autoreactive T cells bypass negative selection and respond to self-antigen stimulation during infection. J Exp Med (2012) 209(10):1769-79. doi:10.1084/jem.20120905

72. Buckner JH, Van Landeghen M, Kwok WW, Tsarknaridis L. Identification of type II collagen peptide 261-273-specific T cell clones in a patient with 
relapsing polychondritis. Arthritis Rheum (2002) 46(1):238-44. doi:10.1002/ 1529-0131(200201)46:1<238::AID-ART10030>3.0.CO;2-M

73. Hebeisen M, Baitsch L, Presotto D, Baumgaertner P, Romero P, Michielin O, et al. SHP-1 phosphatase activity counteracts increased $\mathrm{T}$ cell receptor affinity. J Clin Invest (2013) 123(3):1044-56. doi:10.1172/JCI65325

74. Falta MT, Fontenot AP, Rosloniec EF, Crawford F, Roark CL, Bill J, et al. Class II major histocompatibility complex-peptide tetramer staining in relation to functional avidity and $\mathrm{T}$ cell receptor diversity in the mouse CD4(+) $\mathrm{T}$ cell response to a rheumatoid arthritis-associated antigen. Arthritis Rheum (2005) 52(6):1885-96. doi:10.1002/art.21098

75. Matsui K, Boniface JJ, Reay PA, Schild H, Fazekas de St Groth B, Davis MM. Low affinity interaction of peptide-MHC complexes with $\mathrm{T}$ cell receptors. Science (1991) 254(5039):1788-91. doi:10.1126/science.1763329

76. Jang MH, Seth NP, Wucherpfennig KW. Ex vivo analysis of thymic CD4 $\mathrm{T}$ cells in nonobese diabetic mice with tetramers generated from I-A(g7)/ class II-associated invariant chain peptide precursors. JImmunol (2003) 171(8):4175-86. doi:10.4049/jimmunol.171.8.4175

77. Day CL, Seth NP, Lucas M, Appel H, Gauthier L, Lauer GM, et al. Ex vivo analysis of human memory CD4 T cells specific for hepatitis $\mathrm{C}$ virus using MHC class II tetramers. J Clin Invest (2003) 112(6):831-42. doi:10.1172/JCI200318509
78. Lucas M, Day CL, Wyer JR, Cunliffe SL, Loughry A, McMichael AJ, et al. Ex vivo phenotype and frequency of influenza virus-specific CD4 memory T cells. J Virol (2004) 78(13):7284-7. doi:10.1128/JVI.78.13.72847287.2004

79. Barnes E, Ward SM, Kasprowicz VO, Dusheiko G, Klenerman P, Lucas M. Ultra-sensitive class I tetramer analysis reveals previously undetectable populations of antiviral CD8+ T cells. Eur J Immunol (2004) 34(6):1570-7. doi:10.1002/eji.200424898

Conflict of Interest Statement: AKS is an inventor of patent WO 2010032022 "Use of protein kinase inhibitor to detect immune cells, such as T-cells". The authors declare no other conflicts of interest.

Copyright (C) 2018 Dolton, Zervoudi, Rius, Wall, Thomas, Fuller, Yeo, Legut, Wheeler, Attaf, Chudakov, Choy, Peakman and Sewell. This is an open-access article distributed under the terms of the Creative Commons Attribution License (CC BY). The use, distribution or reproduction in other forums is permitted, provided the original author(s) and the copyright owner are credited and that the original publication in this journal is cited, in accordance with accepted academic practice. No use, distribution or reproduction is permitted which does not comply with these terms. 